\title{
Development of a Flat Type Six-Axis Stage Based on Piezoelectric Actuators
}

\author{
Hau-Wei Lee, ${ }^{1}$ Tsung-Ting Hsieh, ${ }^{2}$ Chin-Chia Liu, ${ }^{3}$ and Chien-Hung Liu ${ }^{2}$ \\ ${ }^{1}$ Center for Measurement Standards, Industrial Technology Research Institute, Hsinchu 300, Taiwan \\ ${ }^{2}$ Department of Mechanical Engineering, National Chung-Hsing University, Taichung 402, Taiwan \\ ${ }^{3}$ Department of Industrial Education and Technology, National Changhua University of Education, Changhua 500, Taiwan
}

Correspondence should be addressed to Chien-Hung Liu; carus@dragon.nchu.edu.tw

Received 18 May 2014; Accepted 1 July 2014; Published 25 September 2014

Academic Editor: Teen-Hang Meen

Copyright (C) 2014 Hau-Wei Lee et al. This is an open access article distributed under the Creative Commons Attribution License, which permits unrestricted use, distribution, and reproduction in any medium, provided the original work is properly cited.

\begin{abstract}
This study presents and investigates a six-DOF (degrees of freedom) piezoelectric based stage for positioning error compensation. The relationship between the displacement of the piezoelectric actuators and the stage can be computed according to the geometric relationships of the actuators installed. In this study, a feedforward compensator based on the hysteresis model has been designed for compensation and a PI controller was used for positioning. The combination of a feedforward compensator and PI controller gives the stage good positioning and tracking performance. Stage position information is feedback from a six-DOF optical measurement system comprised of three modular two-dimensional measurement devices. Each module employs a quadrant photodiode (QPD), a laser diode, and a lens. The measurement signal is acquired and processed using an FPGA based processor for real time control. The linear and angular positioning resolution is $0.02 \mu \mathrm{m}$ and $0.1 \mathrm{arcsec}$, respectively. When the stage is controlled in a closed loop, the positioning errors are in the range of $\pm 0.1 \mu \mathrm{m}$ and $\pm 0.5 \mathrm{arcsec}$. The stage is controlled to track a sinusoidal wave with an amplitude of $2.5 \mu \mathrm{m}$ and a frequency of $5 \mathrm{~Hz}$; tracking errors were within $\pm 0.1 \mu \mathrm{m}$ and $\pm 0.2 \operatorname{arcsec}$.
\end{abstract}

\section{Introduction}

The recent developments in nanotechnology have resulted in increased use of piezoelectric stages which are now universally used for ultrahigh precision positioning or compensation at the nanolevel because piezoelectric actuators have high resolution and sensitivity. For example, Lee and Kim designed an ultrahigh precision wafer alignment stage [1] which is a combination of a long stroke stage and an ultrahigh precision compensation stage. The long stroke stage is driven by linear motors and the other by piezoelectric actuators. This kind of stage is commonly used for the production of touch panels and semiconductors. A piezoelectric based stage (PZT stage) usually includes piezoelectric actuators and flexure hinges. There are two types of flexure hinge in common use, the circular notch and the spherical notch types. In addition to this, Jywe et al. developed an arc flexible body and this was integrated with a spherical notch flexure hinge to make a five-DOF PZT stage [2]. Flexure hinges can be applied to displacement/force transmission, reduction, and enlargement. For instance, Shiou et al. presented a nanostage that can increase the displacement of a piezoelectric actuator [3], and the stage position data is feedback by capacitance probes. The positioning, steady state, and tracking errors of this stage are in the range of $\pm 2 \mathrm{~nm}$ and $\pm 100 \mathrm{~nm}$, respectively. Kim et al. proposed a one-dimensional PZT stage to increase displacement to a few millimeters [4]. Unlike the former, Guo et al. developed a piezoelectric based movement module that reduces the displacement of the stage but increases positioning resolution [5]. Although flexure hinges can be designed to increase the displacement of a stage, it causes positioning performance becoming low as well as they are difficult to design. However, since the moving stroke of an ultrahigh precision production machine is usually less than 

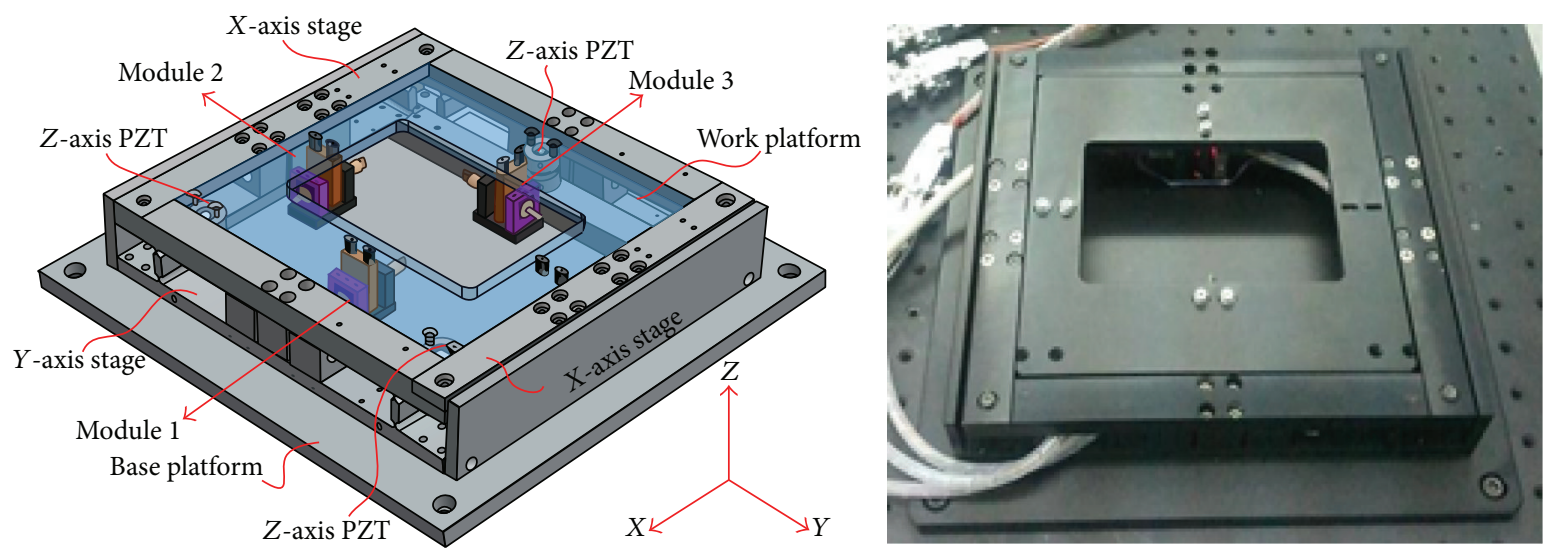

FIGURE 1: The six-DOF compensation stage.

twenty micrometers, a flexure hinge to increase displacement is unnecessary. Note that some commonly used measuring devices have been described in Fleming's study [6].

Several kinds of multi-DOF stage have been proposed. For instance, Polit and Dong developed a two-dimensional PZT stage, which is of compact size, light in weight, and controlled by a feedback controller. Stage position was measured by capacitance probes [7]. Shimizu et al. developed a two-dimensional PZT stage where stage position was measured by a laser interferometer; resolution of the stage could be $10 \mathrm{~nm}$ [8]. Kim and Gweon presented a compact dimension nanostage [9]. Displacement of the stage was measured by capacitance probes installed inside the stage. Linear and angular positioning resolution of the stage were $5 \mathrm{~nm}$ and 0.025 arcsec, respectively. A six-DOF PZT stage, such as that developed by Fesperman et al., is generally built up in stacked configuration [10]. In the Fesperman device, the $x$-axis, $y$-axis, and $\theta_{z}$ movement are driven by linear motors and the $z$-tilt movement uses piezoelectric actuators. A stacked six-DOF stage is easy to control, and displacement is easy to measure, as compared to the six-DOF parallel mechanism by Brouwer et al [11]. In general, the actuators of a $z$-tilt stage are usually installed vertically [12]. However, Lee et al. developed a $z$-tilt stage with the actuators installed horizontally [13]. This kind of stage can be very small and flat but is difficult to design.

The two main problems that influence the performance of piezoelectric actuators are hysteresis and creep. Creep is a static problem that can be easily controlled by feedback, but hysteresis needs to be handled by feedforward compensation. Many different proposals for the compensation of hysteresis have been proposed, for instance, Mayergoyz, Leang, and Devasia used a feedforward compensator based on the Preisach Model [14, 15]. After compensation the tracking error can be smaller than $0.08 \mu \mathrm{m}$ during a $10 \mathrm{~Hz}$ sinusoidal wave [16]; Lin and Chen used a parallel dual feedforward compensator [17], and the tracking error was smaller than $30 \mathrm{~nm}$; other investigators also studied the problem $[15,18-22]$. In addition to the Preisach Model, many other approaches were made to the problem of hysteresis compensation: the approximated polynomial model [23], the
Bouc-Wen [24], the Duhem [25], the generic differential model [26], the Kim [27], and the Maxwell slip model [28] were all used. Some researchers used the observer $[29,30]$ and the sliding mode controller [31,32] to reduce the hysteresis effect. A multi-DOF stage needs a multi-DOF measurement system to measure/monitor the positional values. There are many types of multi-DOF measurement system that have been proposed [33-36]. Though these systems can measure multi-DOF positional value, they are difficult to construct for a flat type of multi-DOF stage and are not easier for analysis.

\section{System Construction}

2.1. The Six-DOF Compensating Stage. As shown in Figure 1, the proposed six-DOF compensation stage consists of four parts: a base platform, three PZT stages (the $x$-axis, $y$-axis, and $z$-tilt), three modular two-dimensional measurement devices, and a work platform. The $y$-axis PZT stage is installed on the base platform as seen in Figure 2(a), and the $x$-axis PZT stage is placed on the $y$-axis PZT stage as seen in Figure 2(b). The $z$-tilt PZT stage is installed on the $x$-axis stage and work platform placed on the $z$-tilt stage as seen in Figure 2(c). The number and installed position of the piezoelectric actuators is shown in Figure 3. The six-DOF movement is described as follows: the $x$-axis movement uses $P_{x 1}$ and $P_{x 2}$; the $y$-axis movement uses $P_{y 1}$ and $P_{y 2}$; Yaw movement (i.e., $\theta_{z}$ motion) uses $P_{x 1}, P_{x 2}, P_{y 1}$, and $P_{y 2} ; z$-tilt movement uses $P_{z 1}, P_{z 2}$, and $P_{z 3}$.

2.2. The Two-Dimensional Measurement Module. The twodimensional measurement module comprises a laser diode fixed to the base platform, a lens linked with the work platform, and a quadrant photodiode (QPD) fixed to the base platform, as seen in Figure 4. Note that the lens and base platform have no connection. The measurement method is illustrated in Figure 5. When the stage moves with a displacement of $\Delta L$, the displacement of the light spot 


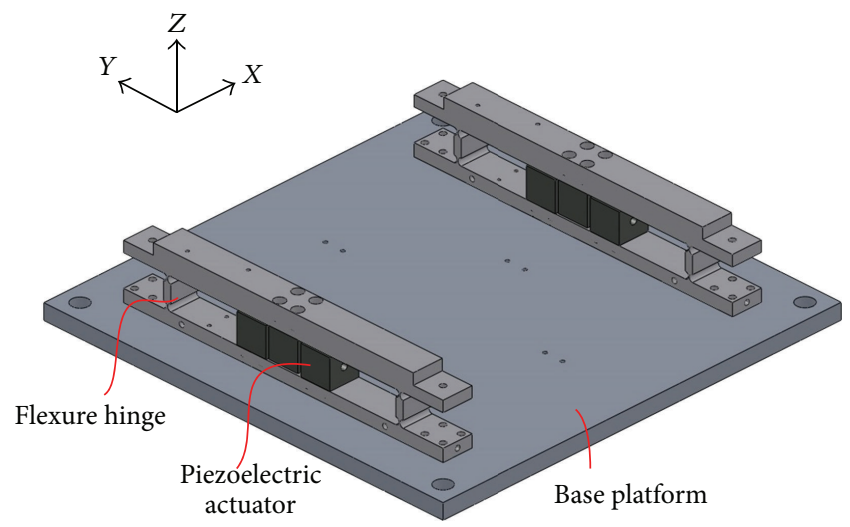

(a)

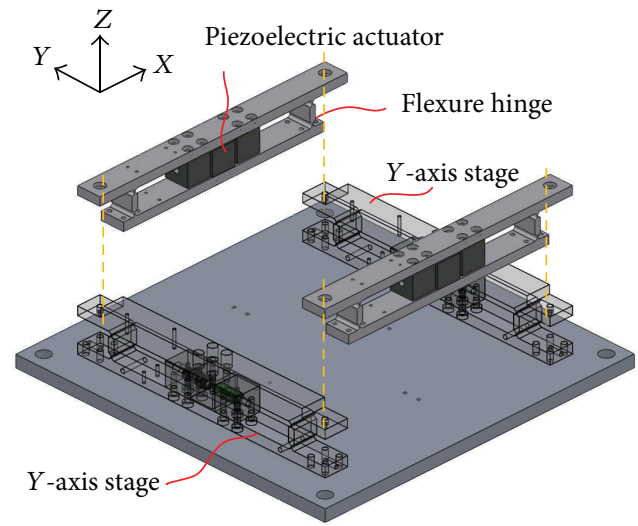

(b)

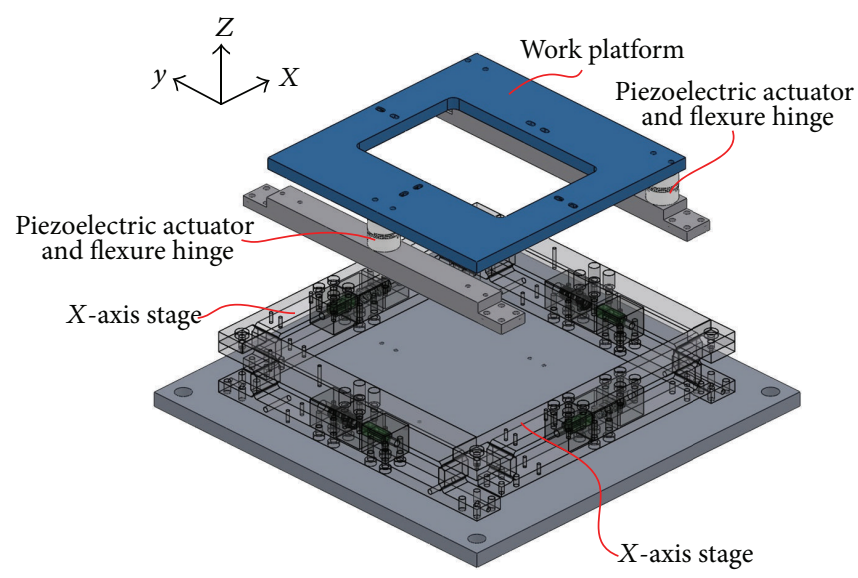

(c)

FIGURE 2: Illustration of the six-DOF stage construction: (a) $Y$-axis stage is installed on the base platform; (b) $x$-axis is placed on the $y$-axis stage; (c) $z$-tilt stage is on the $x$-axis stage and the work platform is fixed to the top of the stack.

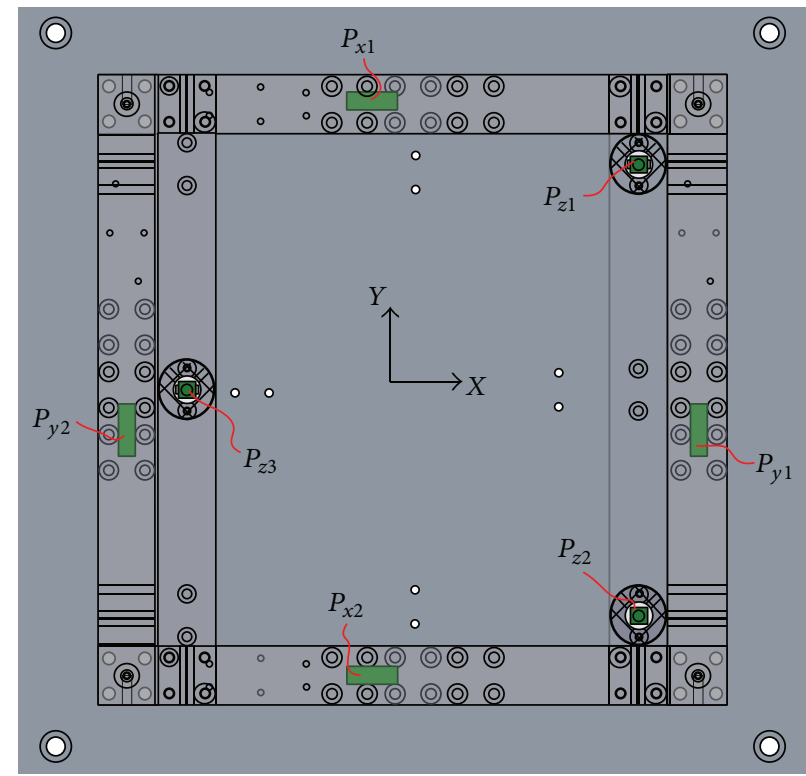

FIGURE 3: Number and installed position of each piezoelectric actuator. 


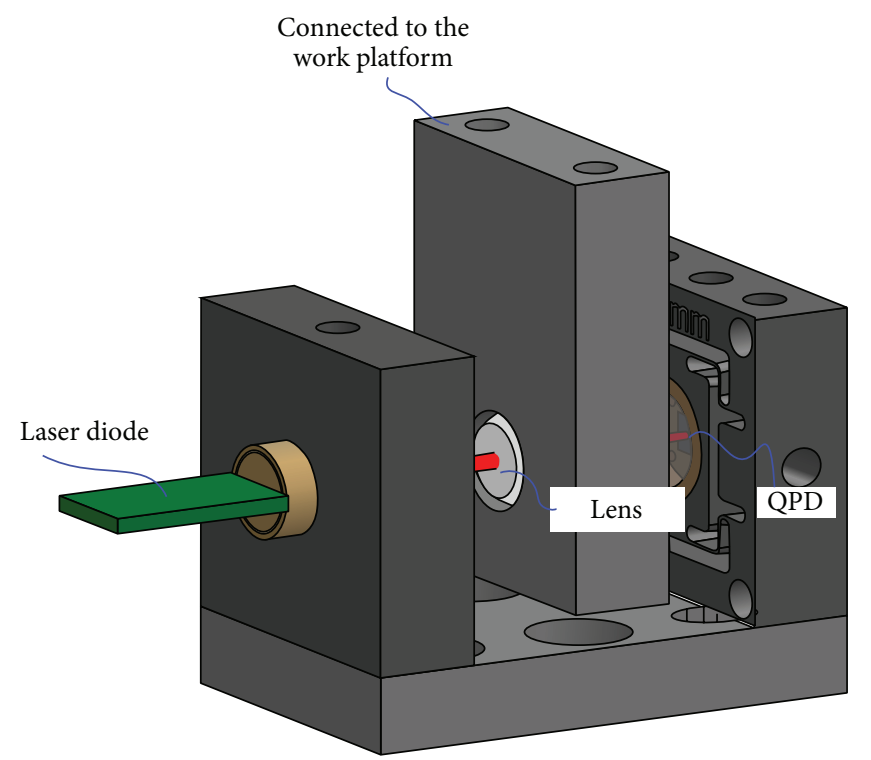

FIgURE 4: Structure of the modular two-dimensional measurement device.

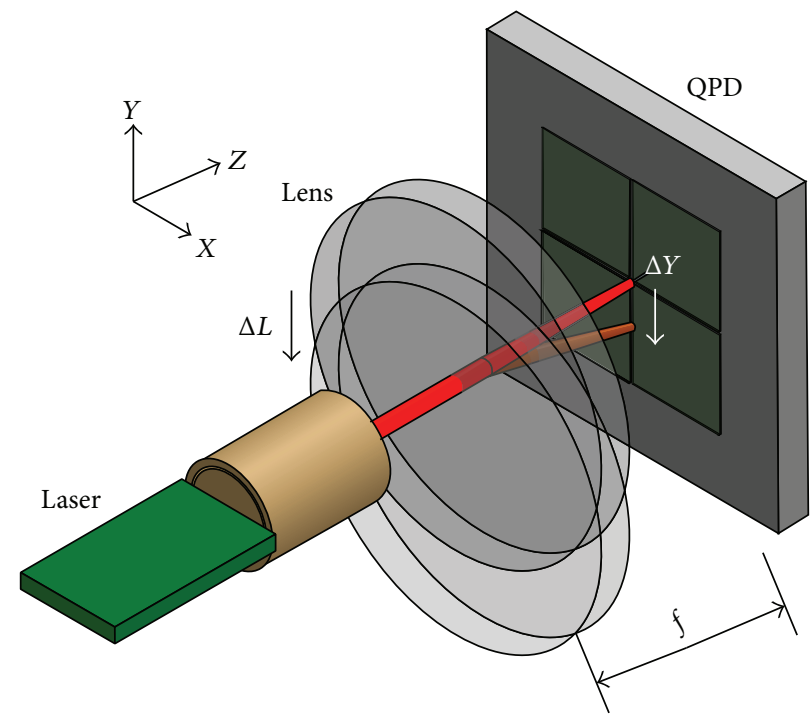

FIGURE 5: Measurement concept diagram of the two-dimensional measurement module.

projected onto the QPD, denoted by $\Delta y$, can be measured. Let $f$ be the focal length of the lens, and the output signal of QPD of $x$ - and $y$-axis is $V_{x}$ and $V_{y}$, respectively, in volts. Displacements of the $x$ - and $y$-axis of the spot measured from the QPD denoted $q_{x}$ and $q_{y}$, respectively, can be calculated by using the following equation:

$$
\begin{aligned}
& q_{x}=K_{x} V_{x}, \\
& q_{y}=K_{y} V_{y},
\end{aligned}
$$

where $K_{x}$ and $K_{y}$ represent the voltage-displacement conversion constant. This study employed three sets of the twodimensional measurement modules, as seen in Figure 6, to measure the six-DOF displacements of the compensation stage including three linear displacements denoted as $\delta_{x}, \delta_{y}$, and $\delta_{z}$ and three angular displacements denoted as $\theta_{x}, \theta_{y}$, and $\theta_{z}$. Thus, displacement of the stage can be determined using the following equation:

$$
\left[\begin{array}{l}
q_{1 x} \\
q_{1 y} \\
q_{2 x} \\
q_{2 y} \\
q_{3 x} \\
q_{3 y}
\end{array}\right] \cong\left[\begin{array}{cccccc}
0 & 1 & 0 & 0 & 0 & d_{1} \\
0 & 0 & 1 & 0 & d_{1} & 0 \\
0 & -1 & 0 & 0 & 0 & 0 \\
0 & 0 & 1 & -\left|d_{2}\right| & 0 & 0 \\
1 & 0 & 0 & 0 & 0 & 0 \\
0 & 0 & 1 & 0 & -\left|d_{3}\right| & 0
\end{array}\right] \cdot\left[\begin{array}{c}
\delta_{x} \\
\delta_{y} \\
\delta_{z} \\
\theta_{x} \\
\theta_{y} \\
\theta_{z}
\end{array}\right] \triangleq \mathbf{M} \cdot \vec{s}_{\text {stage }}
$$




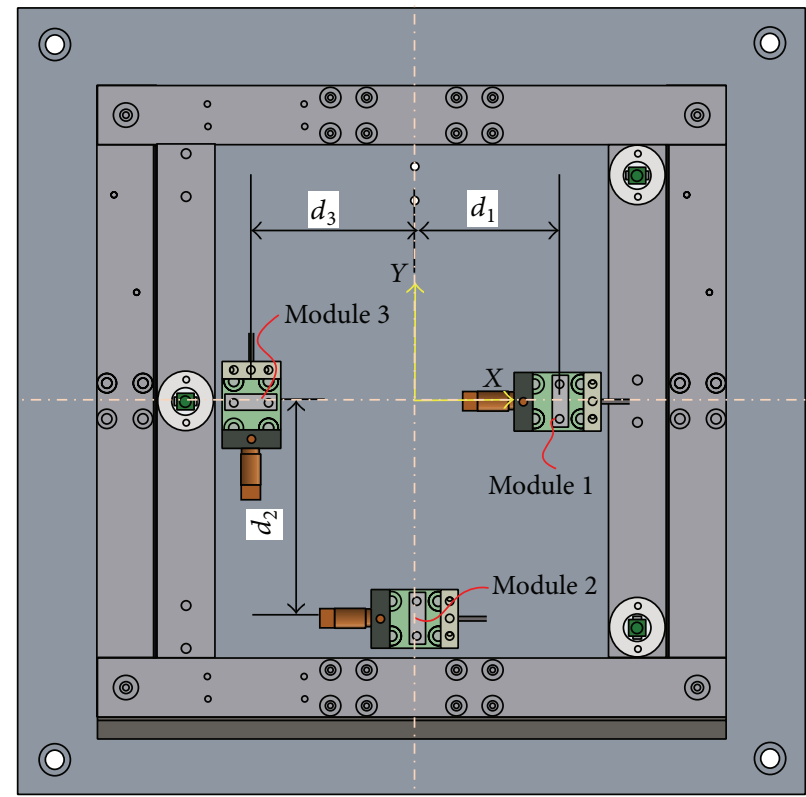

FIgURE 6: The installed positions of each two-dimensional measurement module.

where $q_{i x}$ and $q_{i y}$ represent the $x$ - and $y$-axis displacement of the $i$ th two-dimensional measurement module, respectively; $d_{i}$ is the distance between $i$ th two-dimensional measurement module and the center of the stage.

\section{Control of the Stage}

3.1. Stage Modeling. Because the $y$-axis and yaw movement of the compensating stage are operated by the $y$-axis stage, the stage is analyzed first from the $y$-axis PZT stage. As can be seen in Figure 7(a), the coordinate systems are defined as follows: $\{R\}$ represents the origin of the stage, which is the reference position of the stage kinematic model; $\{O\}$ represents the center of the six-DOF compensation stage; $\left\{P_{Y 1}\right\}$ and $\left\{P_{Y 2}\right\}$ represent the initial position of $P_{Y 1}$ and $P_{Y 2}$ PZT stages, respectively; $\left\{P_{Y 1}^{\prime}\right\}$ and $\left\{P_{Y 2}^{\prime}\right\}$ represent the desired position of $P_{Y 1}$ and $P_{Y 2}$ PZT stages, respectively, when the six-DOF compensating stage is at the required position. Assuming the $y$-axis linear displacement of the compensating stage is $\vec{s}_{y}=\left[\begin{array}{lll}0 & \delta_{y} & 0\end{array}\right]^{T}$ (i.e., vector of the stage moved from $\{R\}$ to $\{O\})$, the distance between the $P_{Y i}$ and $\{R\}$ represents $\vec{d}_{y i}=\left[\begin{array}{lll}d_{y i-x} & d_{y i_{-} y} & 0\end{array}\right]^{T}$, and displacement of $P_{Y i}$ is $\vec{s}_{y i}=$ $\left[\begin{array}{lll}0 & \delta_{y i_{-} y} & 0\end{array}\right]^{T}(i=1,2)$. Thus, the $y$-direction kinematic model is

$$
\begin{gathered}
\vec{s}_{y i}=\vec{s}_{y}+\mathbf{R}_{\mathbf{z i}} \cdot \vec{d}_{y i}-\vec{d}_{y i}, \\
\mathbf{R}_{\mathbf{z} 1}=\left[\begin{array}{ccc}
\cos \theta_{z 1} & -\sin \theta_{z 1} & 0 \\
\sin \theta_{z 1} & \cos \theta_{z 1} & 0 \\
0 & 0 & 1
\end{array}\right] .
\end{gathered}
$$

Because $\theta_{z 1} \ll 1^{\circ}$, (3) can be simplified:

$$
\begin{gathered}
\mathbf{R}_{\mathbf{z} 1} \cong\left[\begin{array}{ccc}
1 & -\theta_{z 1} & 0 \\
\theta_{z 1} & 1 & 0 \\
0 & 0 & 1
\end{array}\right] \\
\delta_{y i_{-} y}=\delta_{y}+d_{y i_{-} x} \theta_{z 1} .
\end{gathered}
$$

Similarly, the $x$-axis kinematic model is

$$
\delta_{x i-x}=\delta_{x}+d_{x i-x} \theta_{z 2} .
$$

Please note that the $x$-and $y$-axes of the PZT stage both contribute yaw motion, and we use $\theta_{z 1}$ and $\theta_{z 2}$ to denote the yaw motion contributed by the $y$ - and $x$-axis PZT stages, respectively. The $x$-axis PZT stage and the $y$-axis PZT stage form a four-bar mechanism as shown in Figure 8. Hence, when the stage is rotated by $\theta_{z 1}$, (6) and (5) should be corrected, as follows:

$$
\begin{gathered}
\delta_{x i_{-} x}=\frac{\delta_{x}+d_{x i-x} \theta_{z 2}}{\cos \theta_{z 1}} \\
\delta_{y i_{-} y}=\delta_{y}+d_{y i_{-} x} \theta_{z 1}+\delta_{x i_{-} x} \sin \theta_{z 1} \\
\cong \delta_{y}+d_{y i_{x}} \theta_{z 1}+\delta_{x i_{x}} \theta_{z 1} \\
=\delta_{y}+d_{y i_{x}} \theta_{z 1}+\left(\delta_{x}+d_{x i_{x}} \theta_{z 2}\right) \theta_{z 1} .
\end{gathered}
$$

From (7), because $\cos \theta_{z 1} \approx 1,(7)$ is completely equal to (5). Similarly, since $\theta_{z 1}$ and $\theta_{z 2}$ are both smaller than one degree and the maximum displacement of $x$-direction is smaller 


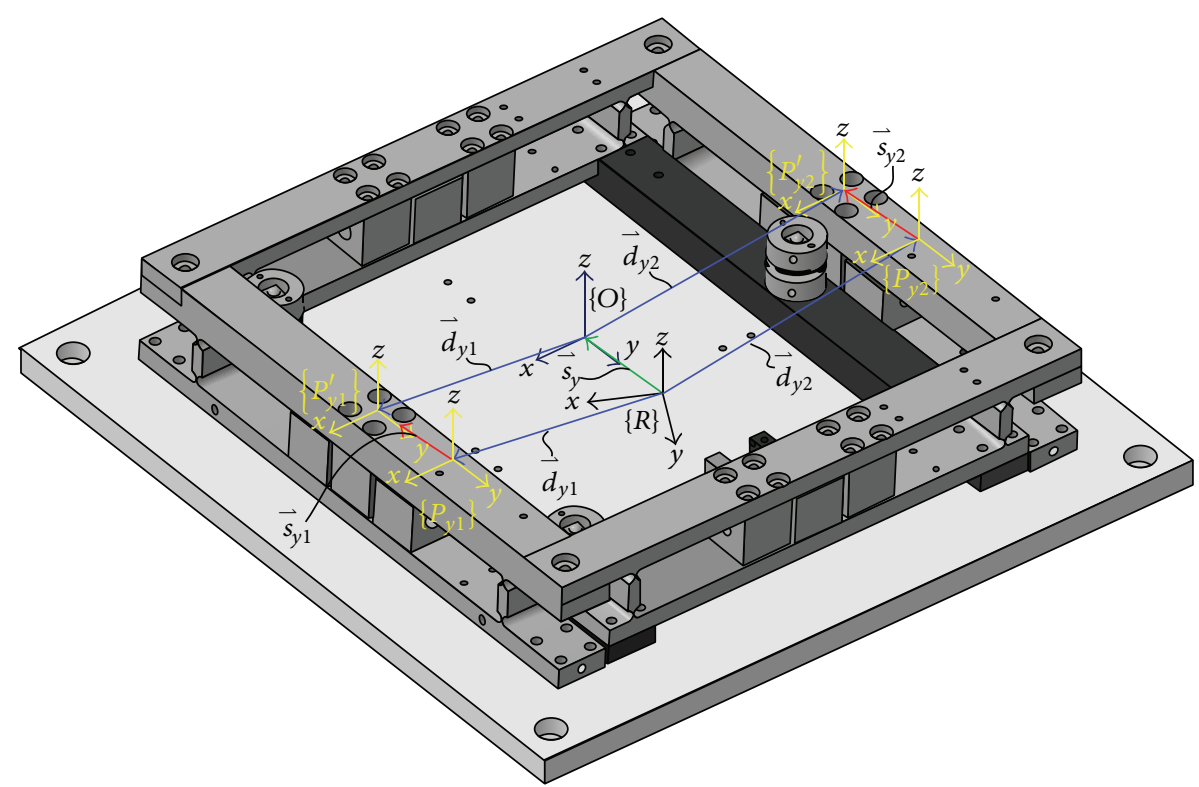

(a)

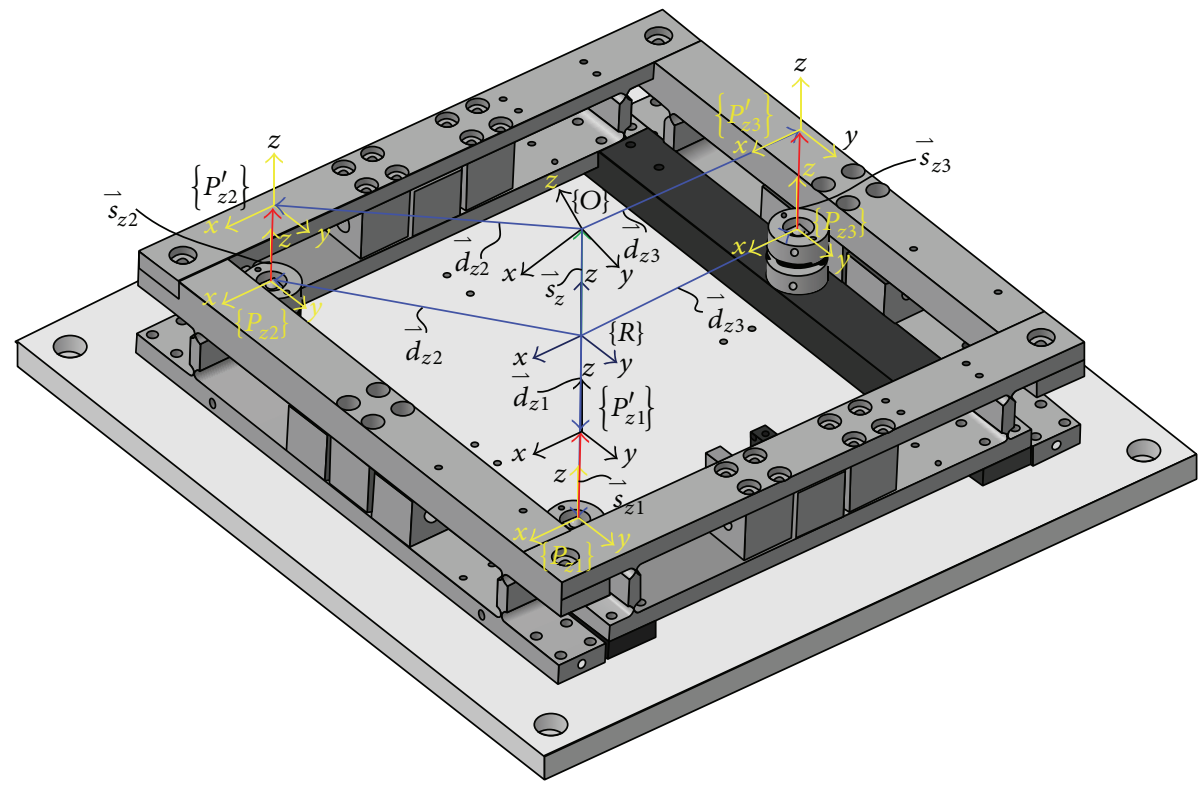

(b)

FIGURE 7: Schematic diagram for kinematic analysis of the six-DOF compensation stage: (a) $y$-axis and yaw movement; (b) $z$-tilt movement.

than twenty micrometers (i.e., $\theta_{z 2} \theta_{z 1} \rightarrow 0$ and $\delta_{x} \theta_{z 1} \rightarrow 0$ ), (8) is completely equal to (5). Suffice it to say that this kind of construct between the $x$ - and $y$-axis PZT stages does not cause a position coupling problem.

The kinematic equation for $z$-tilt motion can be derived according to Figure $7(\mathrm{~b})$. In the plot, coordinate systems $\left\{P_{Z j}\right\}$ represent the initial position of $P_{Z j}$ and $j=1,2$, and 3 . Similarly, $\left\{P_{Z j}^{\prime}\right\}$ is the position of $P_{Z j}$ after the compensation stage is at the required position, and the vector $\vec{d}_{z j}=$ $\left[\begin{array}{lll}d_{y i_{-} x} & d_{y i_{-} y} & d_{y i_{-} z}\end{array}\right]^{T}$ represents the install position of $P_{Z j}$. The displacement vector $\vec{s}_{z j}=\left[\begin{array}{lll}0 & 0 & \delta_{z j_{-} z}\end{array}\right]^{T}$ of $j$ th PZT can be determined by

$$
\vec{s}_{z j}=\vec{s}_{z}+\mathbf{R}_{\mathbf{Y X}} \cdot \vec{d}_{z j}-\vec{d}_{z j}
$$

$$
\mathbf{R}_{\mathbf{Y X}}=\left[\begin{array}{ccc}
\cos \theta_{y} & 0 & \sin \theta_{y} \\
0 & 1 & 0 \\
-\sin \theta_{y} & 0 & \cos \theta_{y}
\end{array}\right]\left[\begin{array}{ccc}
1 & 0 & 0 \\
0 & \cos \theta_{x} & -\sin \theta_{x} \\
0 & \sin \theta_{x} & \cos \theta_{x}
\end{array}\right],
$$




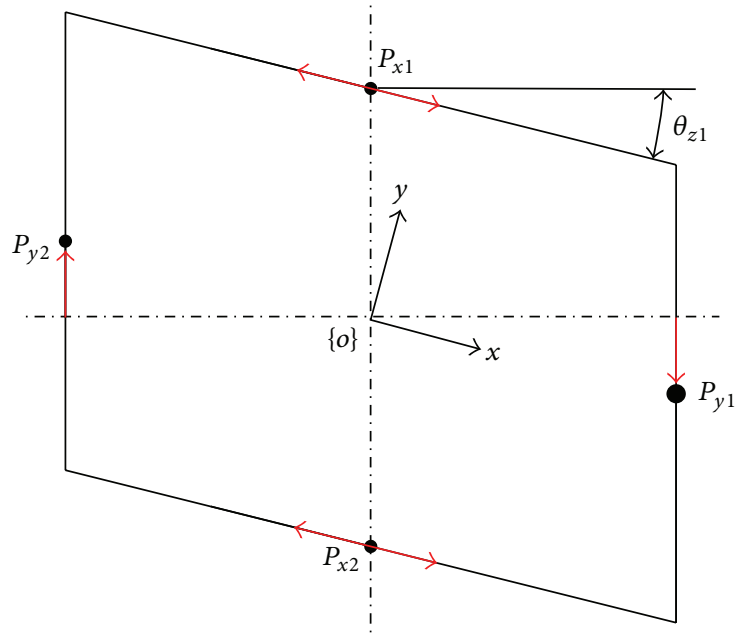

FIGURE 8: When the stage rotates along $\theta_{z 1}, x$-axis movement produces a displacement component of the $y$-axis.

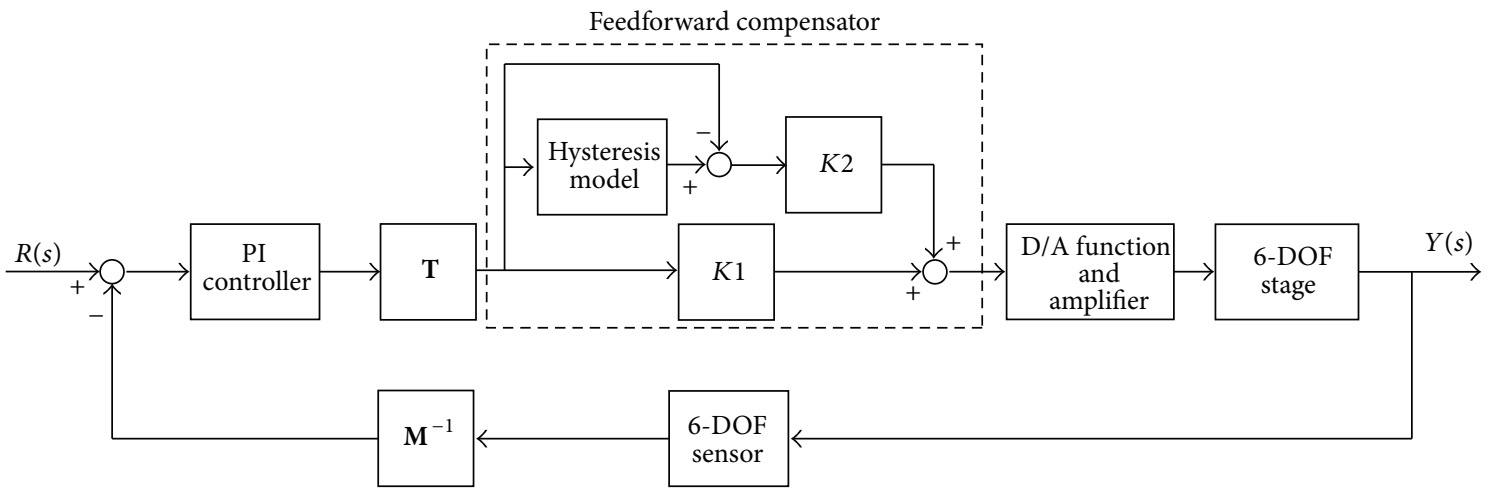

FIGURE 9: Control block diagram of the PZT stage in this study.

where $\vec{s}_{z}=\left[\begin{array}{lll}0 & 0 & \delta_{z}\end{array}\right]^{T}$ represents the required position of the compensating stage. Since $\theta_{y} \ll 1^{\circ}$ and $\theta_{x} \ll 1^{\circ}$, (10) can be simplified as

$$
\mathbf{R}_{\mathbf{Y X}}=\left[\begin{array}{ccc}
1 & 0 & \theta_{y} \\
0 & 1 & 0 \\
-\theta_{y} & 0 & 1
\end{array}\right]\left[\begin{array}{ccc}
1 & 0 & 0 \\
0 & 1 & -\theta_{x} \\
0 & \theta_{x} & 1
\end{array}\right]
$$

Substituting (11) into (9) gives

$$
\delta_{z j_{-} z}=\delta_{z}+d_{y j_{-} y} \theta_{x}-d_{y j_{x}} \theta_{y}
$$

From (7), (8), and (12), the linearized kinematic equation for the stage is

$$
\left[\begin{array}{l}
\delta_{x 1} \\
\delta_{x 2} \\
\delta_{y 1} \\
\delta_{y 2} \\
\delta_{z 1} \\
\delta_{z 2} \\
\delta_{z 3}
\end{array}\right]=\left[\begin{array}{cccccc}
1 & 0 & 0 & 0 & 0 & d_{x 1 \_x} \\
1 & 0 & 0 & 0 & 0 & d_{x 2 \_x} \\
0 & 1 & 0 & 0 & d_{y 1-x} & 0 \\
0 & 1 & 0 & 0 & d_{y 2-x} & 0 \\
0 & 0 & 1 & d_{y 1 \_} & -d_{y 1-x} & 0 \\
0 & 0 & 1 & d_{y 2-y} & -d_{y 2-x} & 0 \\
0 & 0 & 1 & d_{y 3 \_} & -d_{y 3-x} & 0
\end{array}\right]\left[\begin{array}{c}
\delta_{x} \\
\delta_{y} \\
\delta_{z} \\
\theta_{x} \\
\theta_{y} \\
\theta_{z 1} \\
\theta_{z 2}
\end{array}\right],
$$

where $\delta_{v}$ is the displacement of the PZT of $P_{v}(v=$ $x 1, y 2, y 1, y 2, z 1, z 2$, and $z 3$ ). To define the equation above

$$
\vec{s}_{\text {piezo }}=\mathrm{T} \cdot \vec{s}_{\text {stage }}
$$

3.2. Stage Control. In this study, the compensation stage is controlled by the PI controller combined with the feedforward compensator as shown in Figure 9. The gain denoted by $\mathrm{K} 1$ is used for displacement-voltage conversion for PZT, and $\mathrm{K} 2$ is the gain of the feedforward compensator. Here, the hysteresis model for the feedforward compensator is based on the generic differential model [26]. The parameters of each PZT are listed in Table 1. The trajectory of PZT1 before and after compensation is shown in Figure 10(a). The voltage-displacement conversion constant can be found by line fitting from the trajectory after hysteresis compensation. Figure 10(b) shows the residual error is in the range of $\pm 40 \mathrm{~nm}$ after hysteresis compensation.

\section{Experimental Results}

The signal processing flow chart for the six-DOF compensation stage is shown in Figure 11, in which all the signals were 


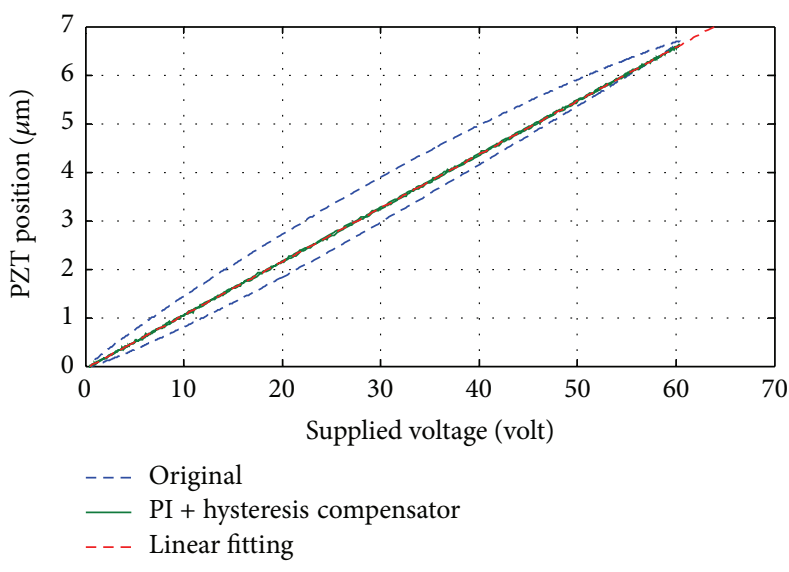

(a)

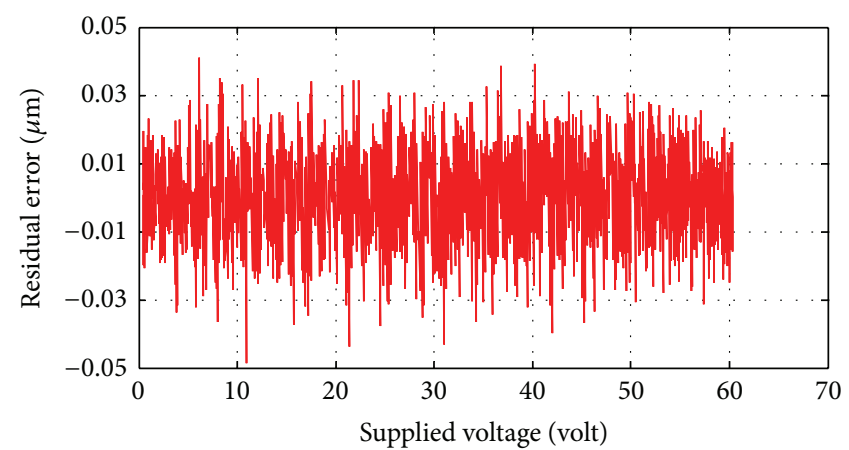

(b)

FIGURE 10: After compensation the hysteresis loop can be reduced: (a) voltage versus PZT position curve; (b) residual error after hysteresis compensated.

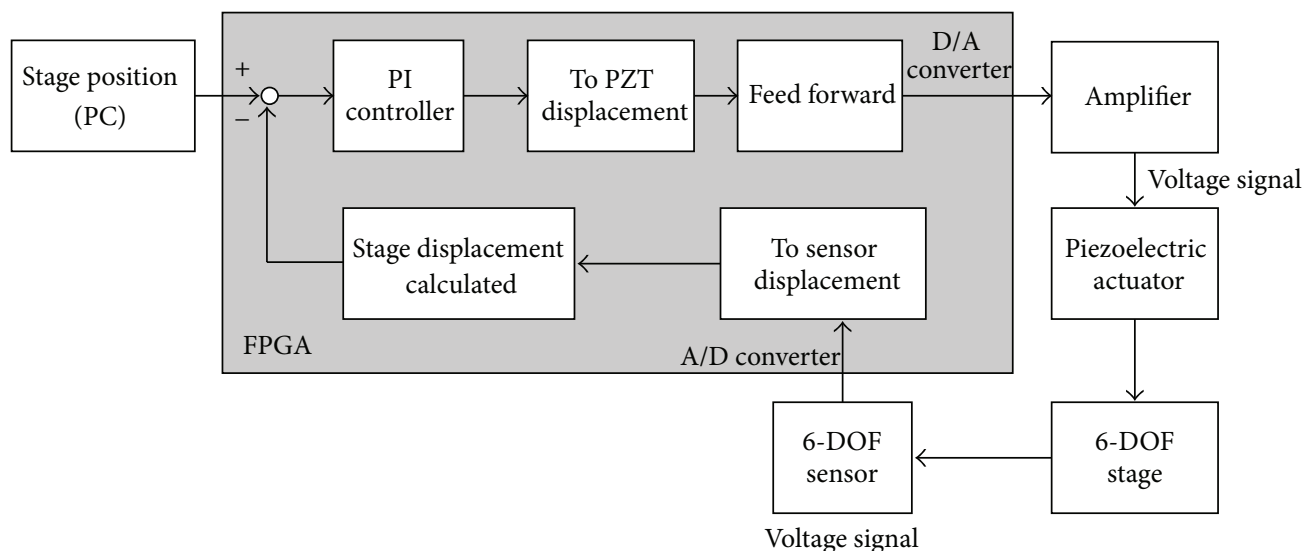

FIGURE 11: Signal processing flow chart of compensation stage control.

TABLE 1: Parameters of the general differential model for each piezoelectric actuator.

\begin{tabular}{lccr}
\hline & $a$ & $b$ & $\alpha$ \\
\hline$P_{x 1}$ & 0.131 & 0.090 & 0.057 \\
$P_{x 2}$ & 0.131 & 0.090 & 0.057 \\
$P_{y 1}$ & 0.139 & 0.097 & 0.048 \\
$P_{y 2}$ & 0.133 & 0.093 & 0.053 \\
$P_{z 1}$ & 0.142 & 0.086 & 0.096 \\
$P_{z 2}$ & 0.131 & 0.078 & 0.091 \\
$P_{z 3}$ & 0.130 & 0.077 & 0.098 \\
\hline
\end{tabular}

processed using an FPGA based processor (NI PCIe 7842R). Before the experiment, the three-DOF measurement system was calibrated by comparison with laser interferometer readings to guarantee the measured positional value. Calibration results are shown in Figure 12.

4.1. Test for Stability and Resolution. Because the compensation stage is driven by piezoelectric actuators and position is feedback from the six-DOF measurement system, creep and thermal drift might affect positional value stability; system stability should be evaluated by the system stability test which also evaluates system noise. The stability test results (Figure 13) show linear stability is about $\pm 20 \mathrm{~nm}$ and angular stability is about $\pm 0.05 \operatorname{arcsec}$ ( for $\theta_{x}$ ) and $\pm 0.1 \operatorname{arcsec}$ (for $\theta_{y}$ and $\theta_{z}$ ). In general, the positioning resolution of a compensation stage can be tested using a stepwise signal and positioning resolution is usually affected by the noise in the measurement system. Thus, the displacement of each step is 


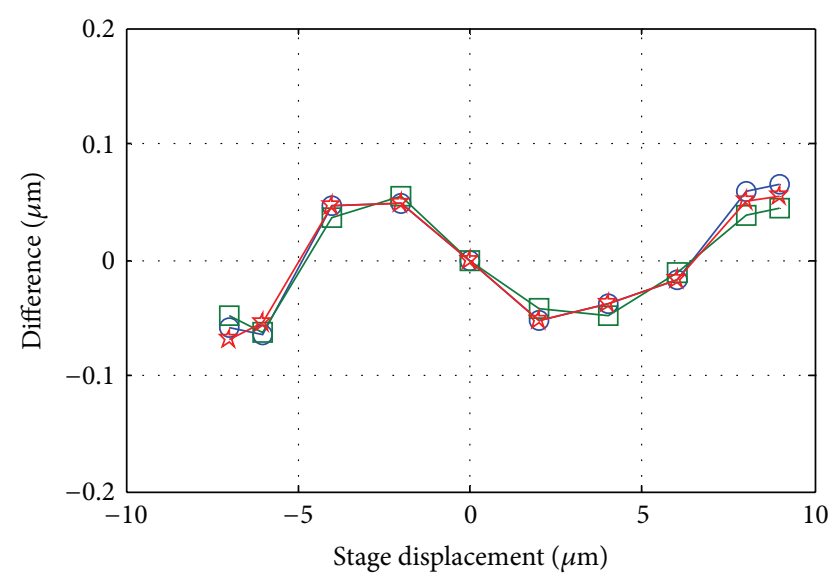

(a)

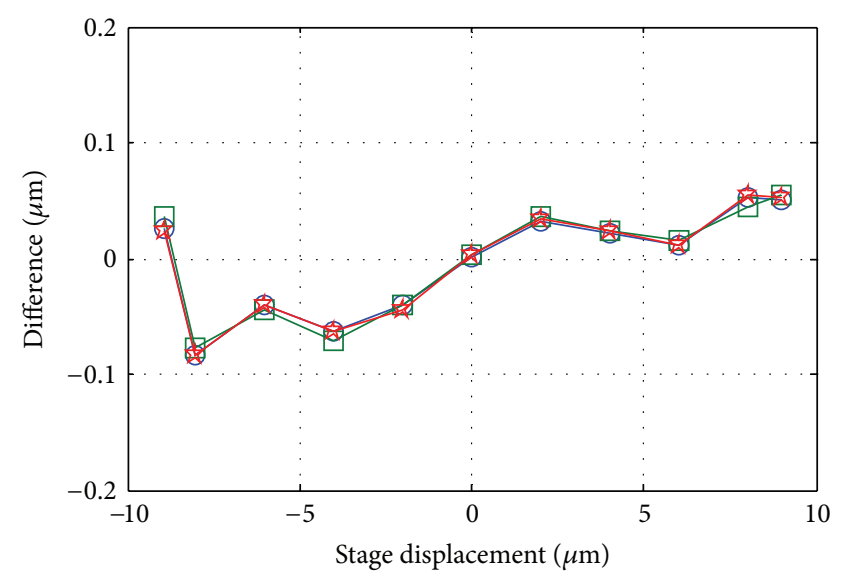

(c)

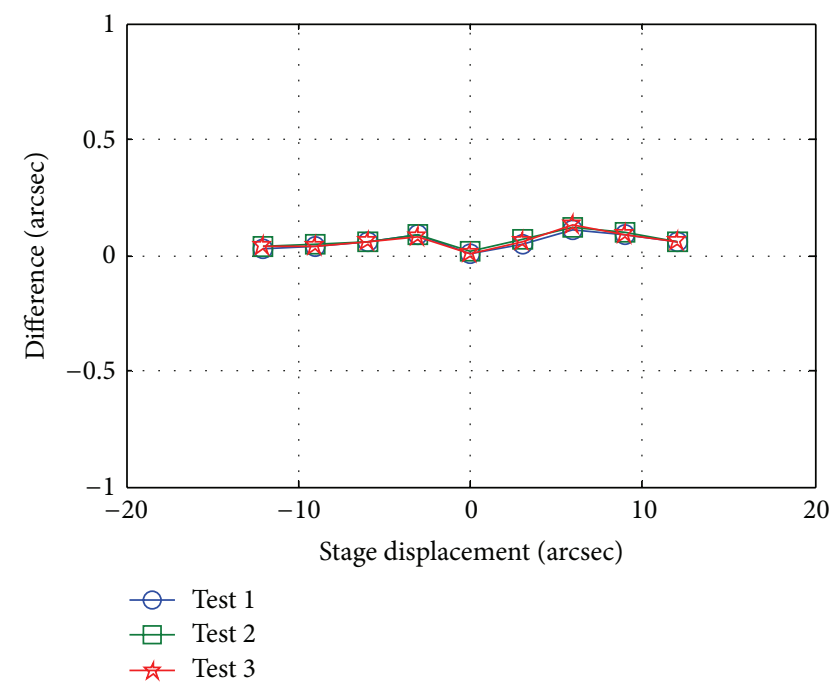

(e)

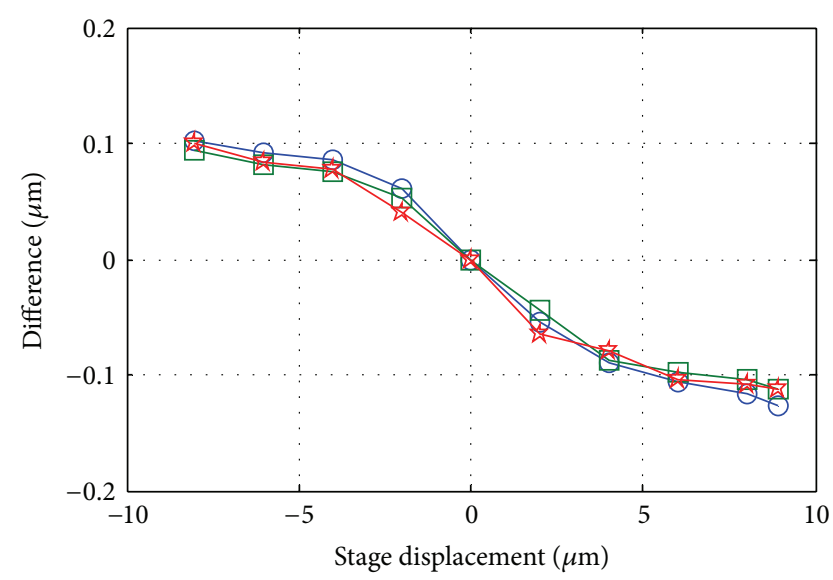

(b)

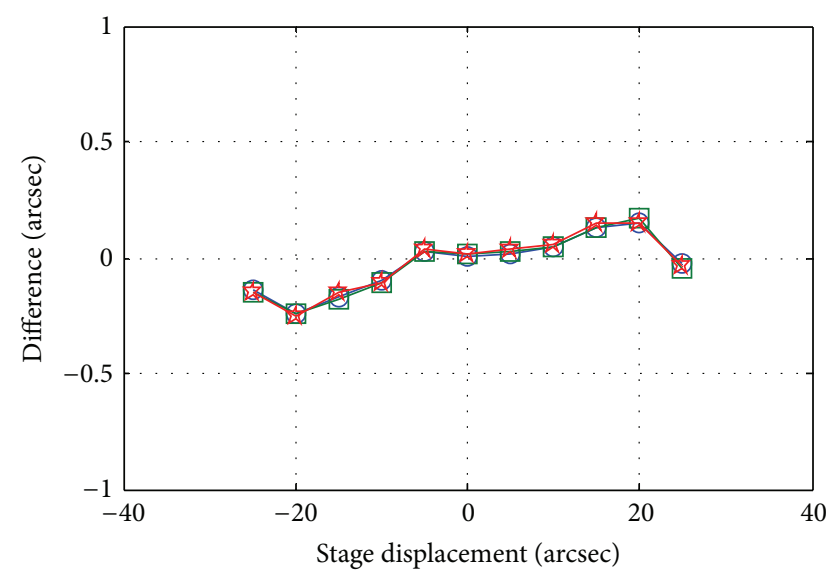

(d)

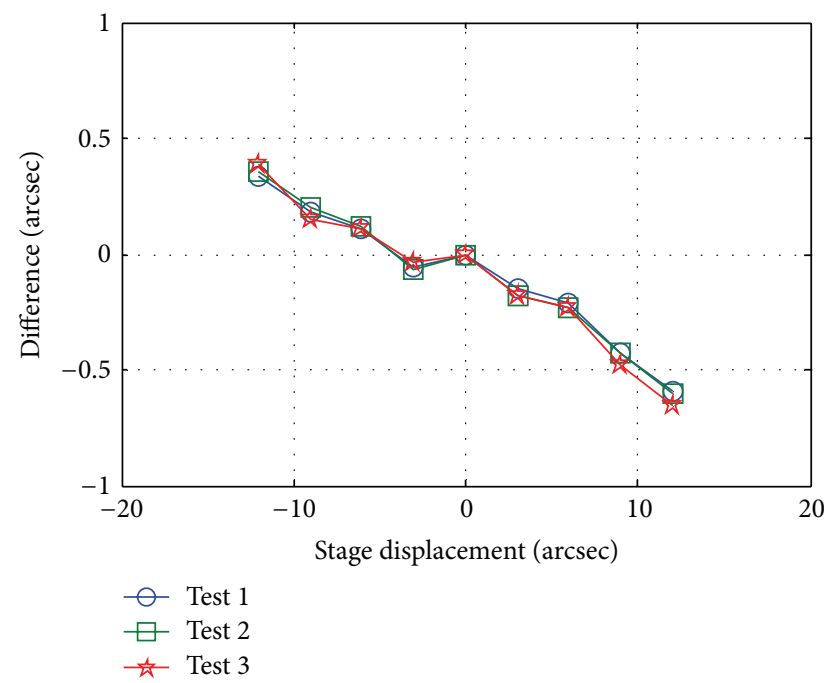

(f)

FIGURE 12: Residual error of the six-DOF measurements after calibration. (a) $x$-axis; (b) $y$-axis; (c) $z$-axis; (d) $\theta_{x}$ rotation; (e) $\theta_{y}$ rotation; (f) $\theta_{z}$ rotation. 


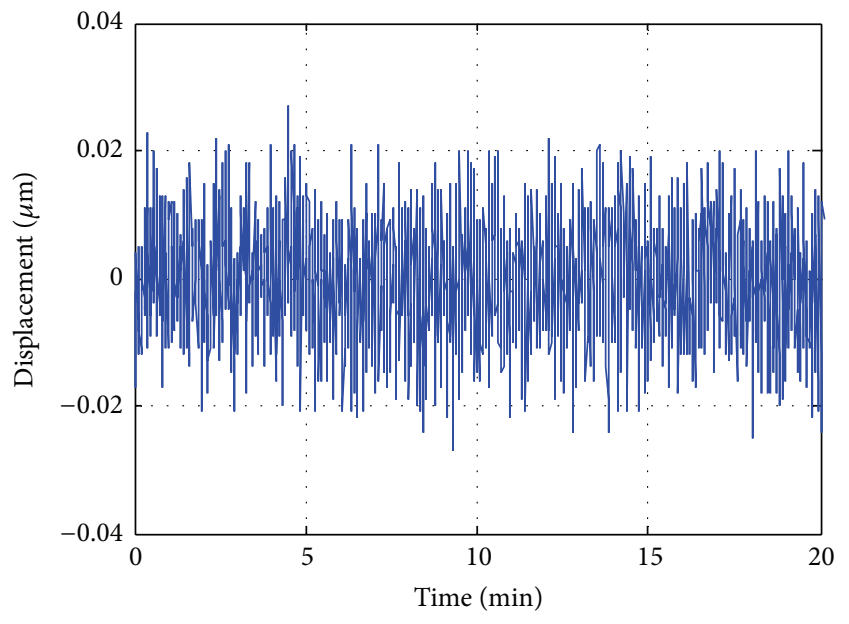

(a)

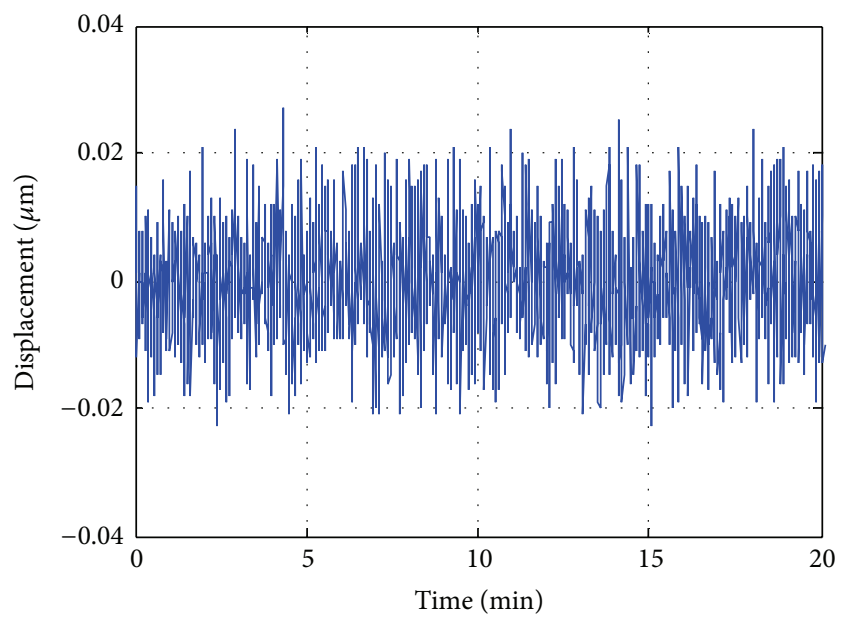

(c)

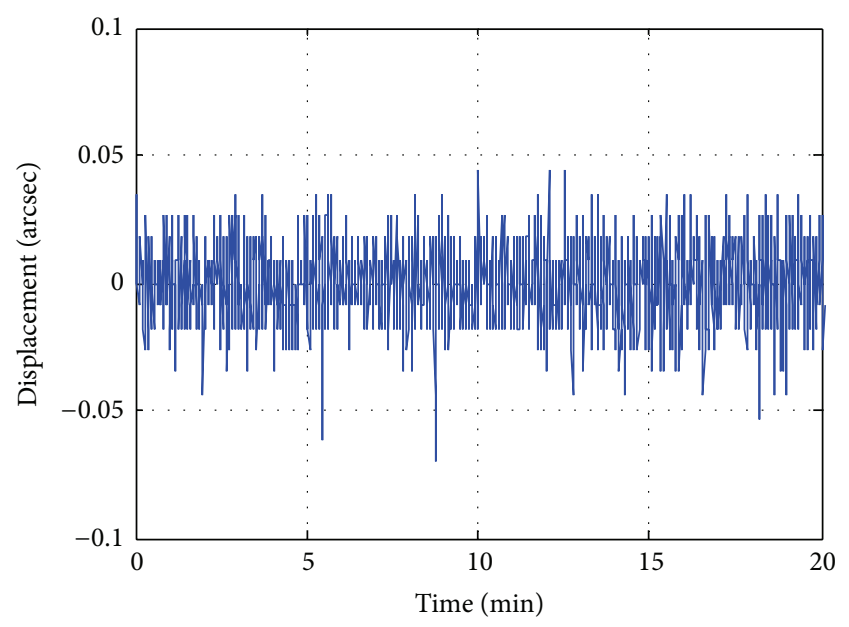

(e)

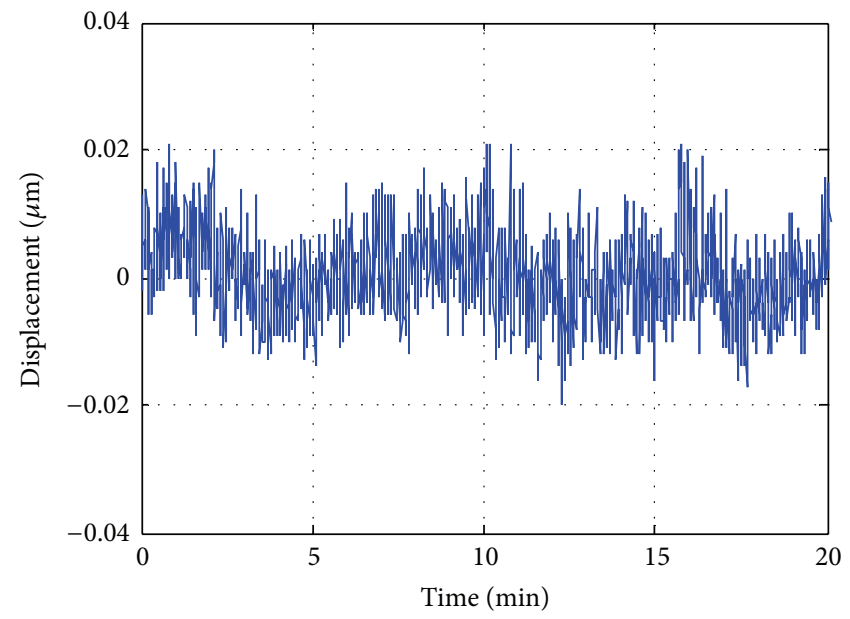

(b)

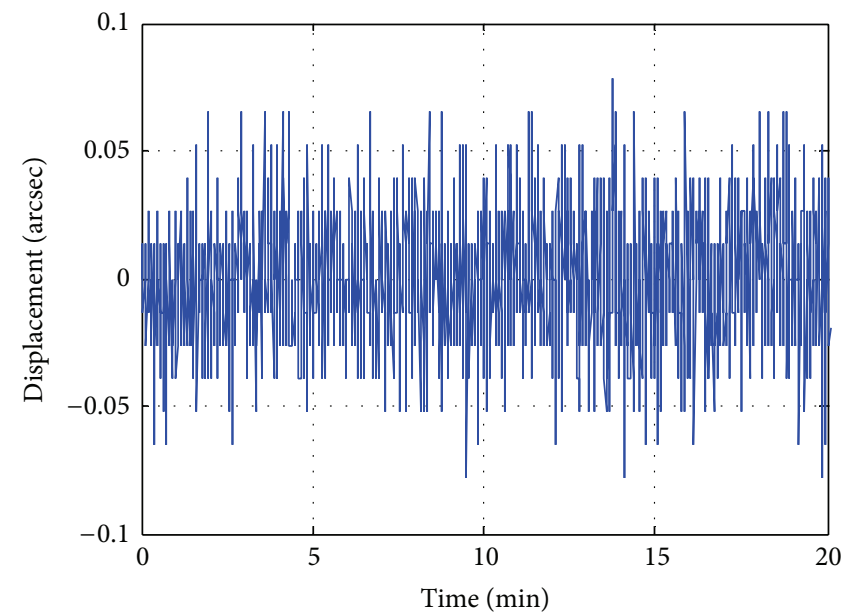

(d)

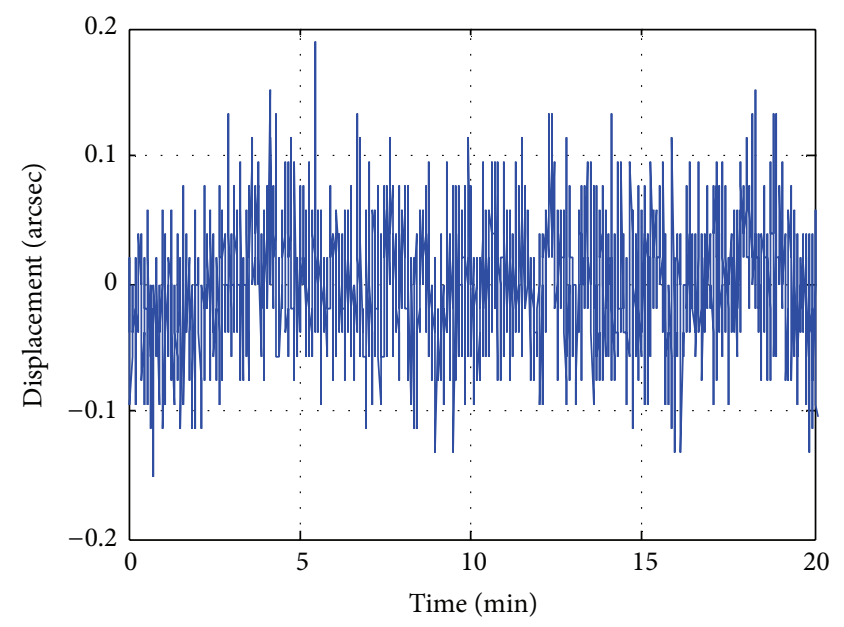

(f)

FIGURE 13: Stability test results for each axis over 20 minutes: (a) $x$-axis; (b) $y$-axis; (c) $z$-axis; (d) $\theta_{X}$; (e) $\theta_{Y}$; (f) $\theta_{Z}$. 


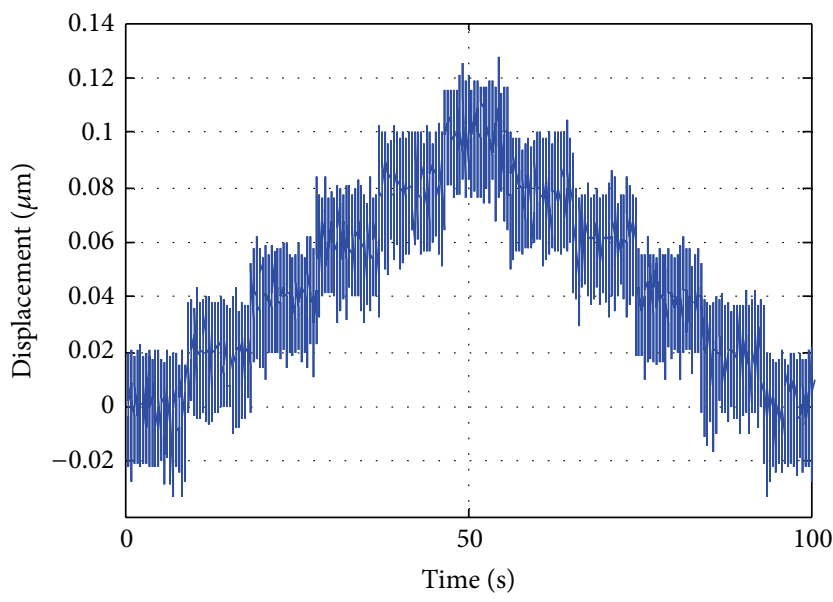

(a)

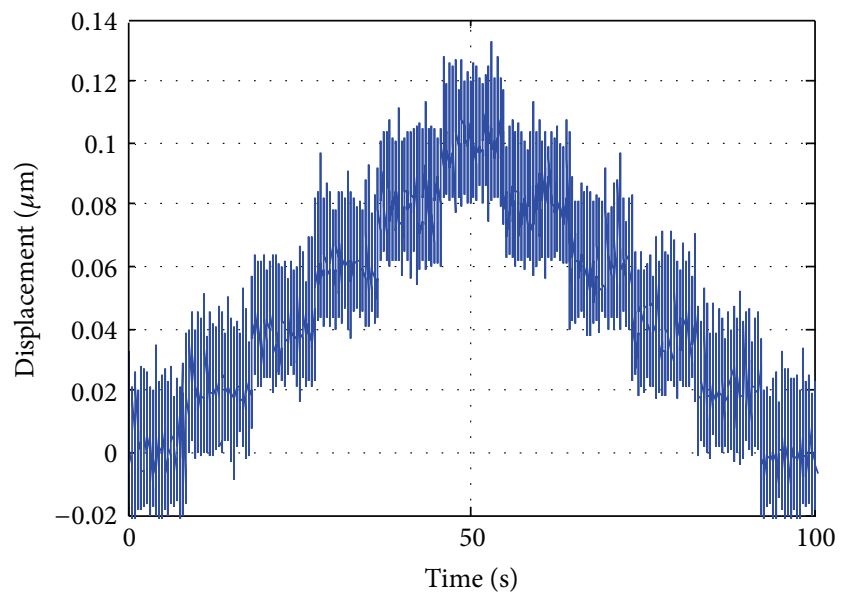

(c)

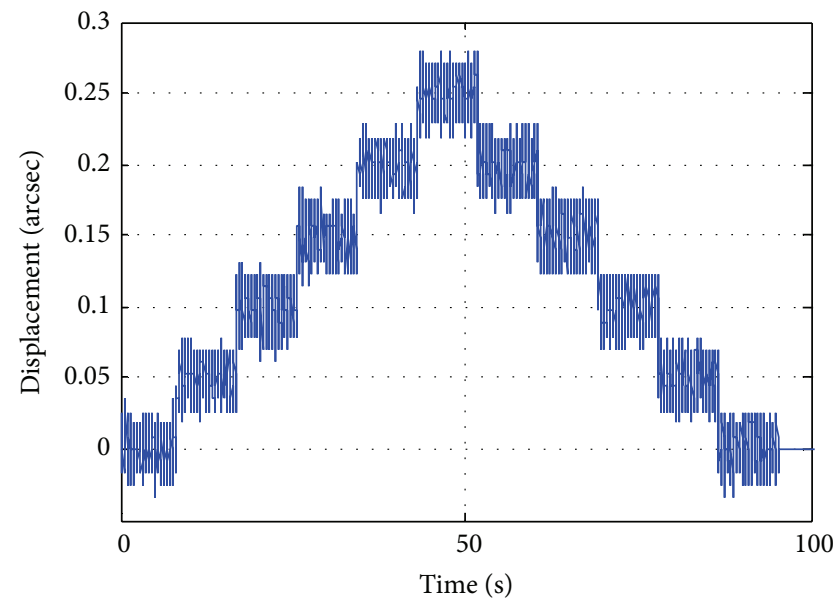

(e)

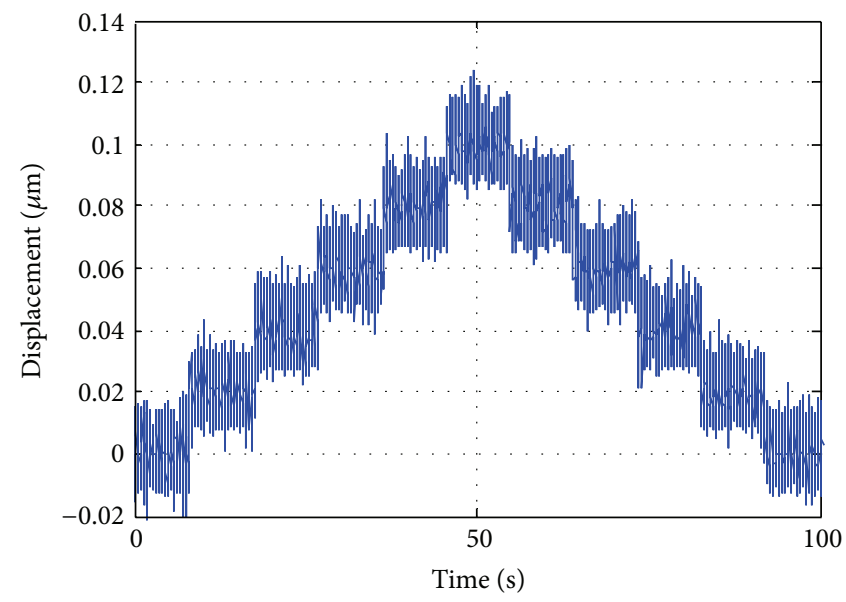

(b)

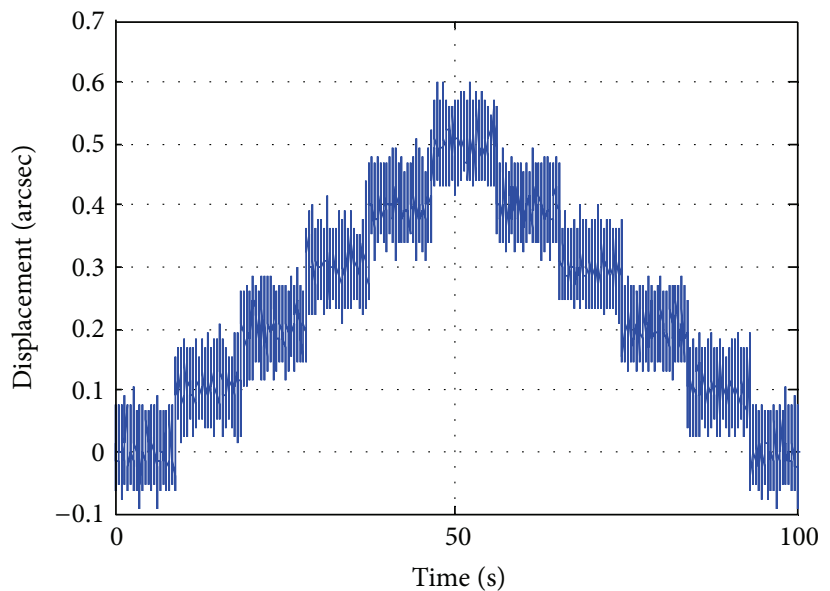

(d)

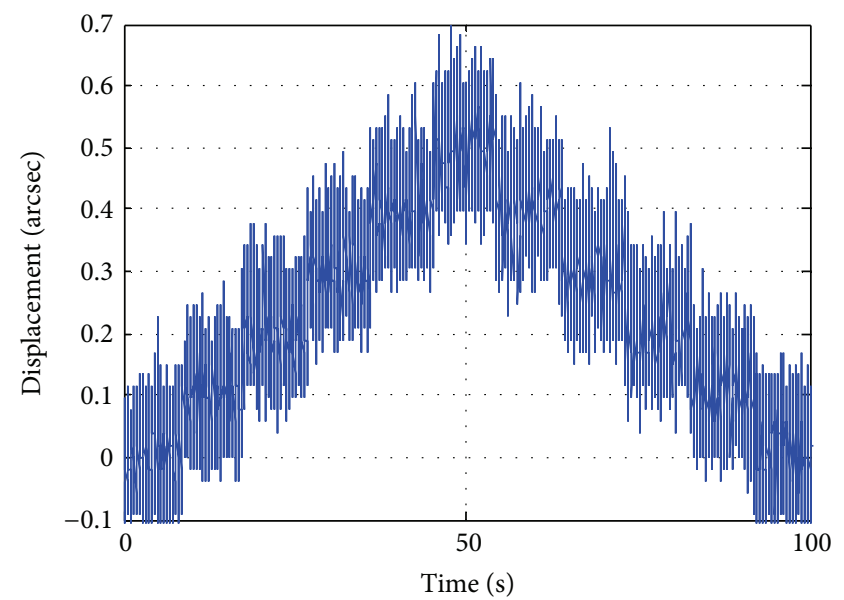

(f)

Figure 14: Stepwise test results for each axis: (a) $x$-axis; (b) $y$-axis; (c) $z$-axis; (d) $\theta_{X}$; (e) $\theta_{Y}$; (f) $\theta_{Z}$. 


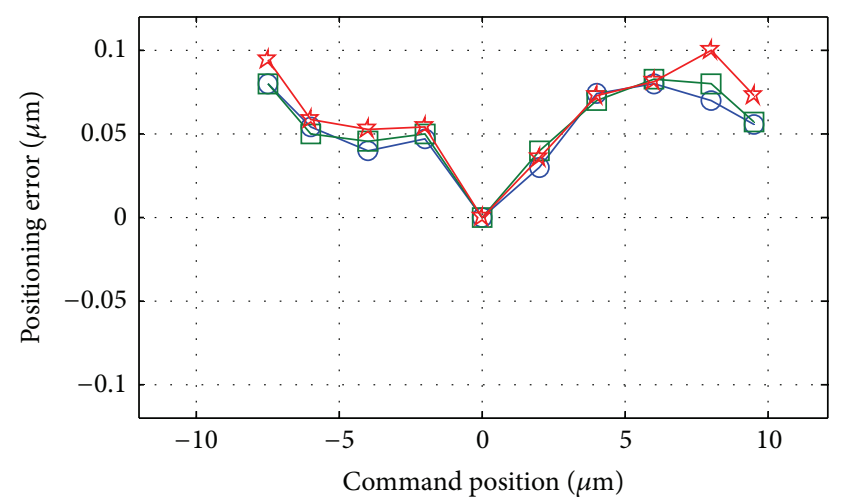

(a)

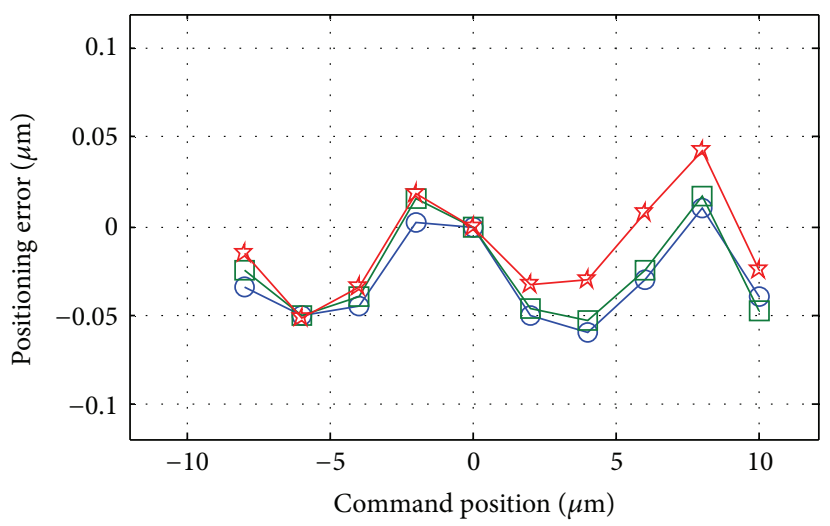

(c)

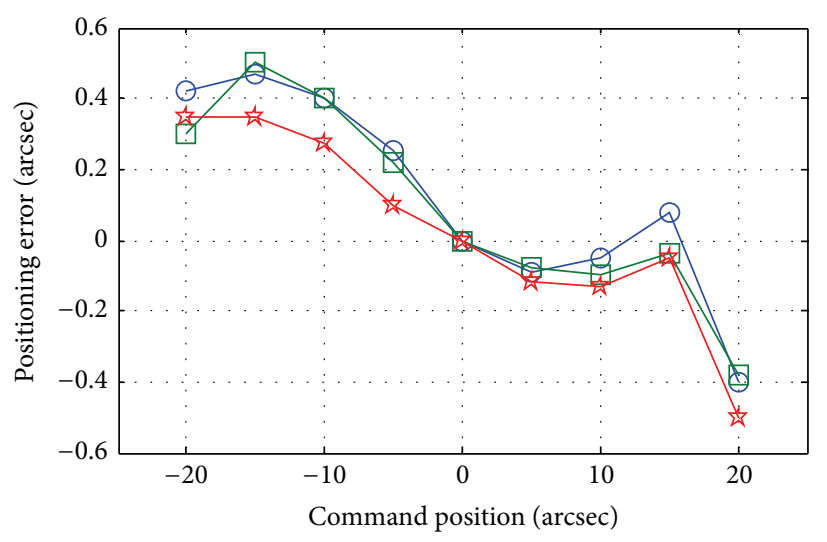

$\smile$ Round 1
$\square$ Round 2
$\square$ Round 3

(e)

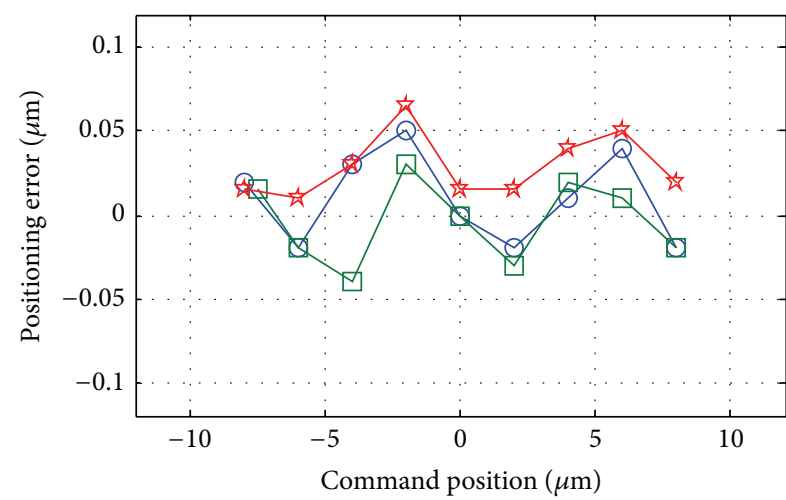

(b)

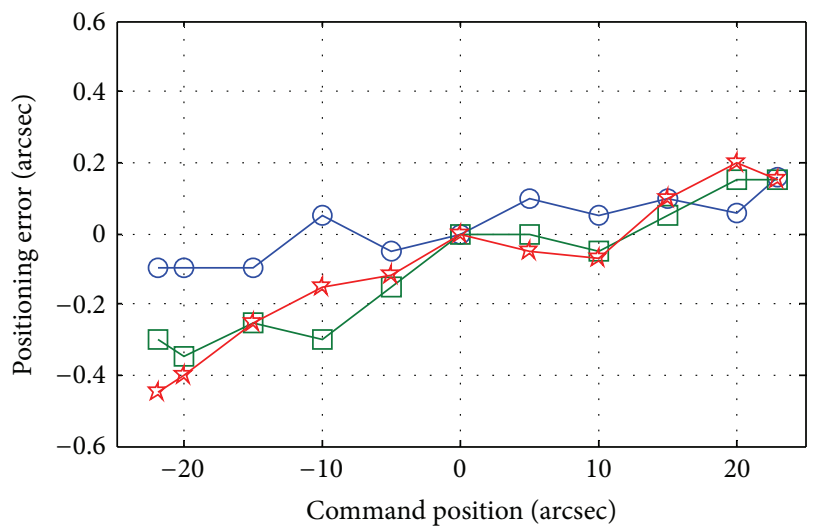

(d)

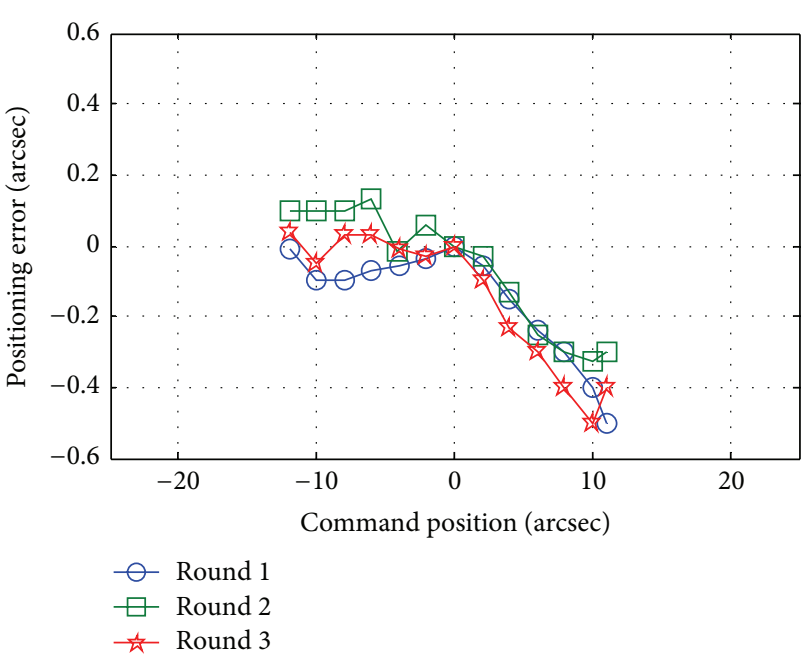

(f)

FIGURE 15: Single-axis displacement verification result ( 3 x test for each axis): (a) $x$-axis; (b) $y$-axis; (c) $z$-axis; (d) $\theta_{X}$; (e) $\theta_{Y}$; (f) $\theta_{Z}$.

set according to the noise of the measurement system. The stepwise test results are shown in Figure 14.

4.2. Single-Axis Movement Verification. This experiment provides verification of the kinematic equations (13). The stage is controlled in a closed loop and moved one axis at a time and this was repeated three times for each axis. Displacement of the stage was measured using the six-DOF measurement system. Experimental results are shown in Figure 15 and show a positioning accuracy of under $0.1 \mu \mathrm{m}$ and $0.5 \mathrm{arcsec}$. 


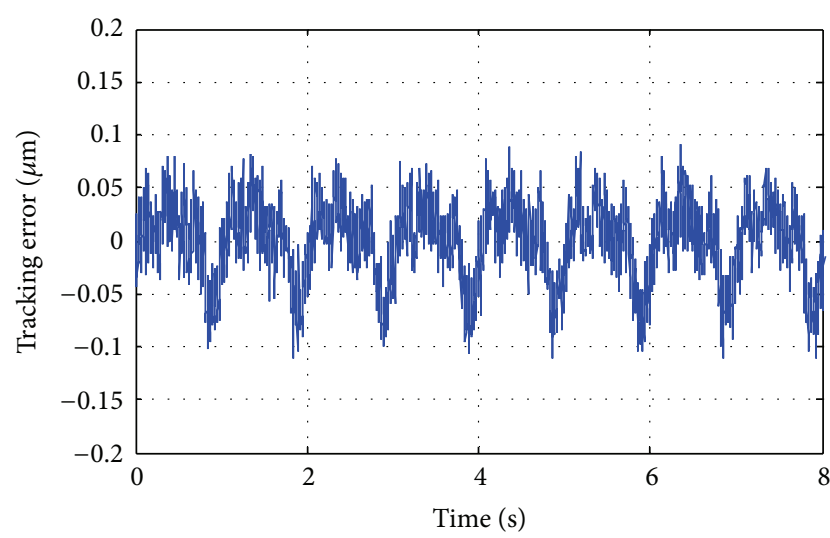

(a)

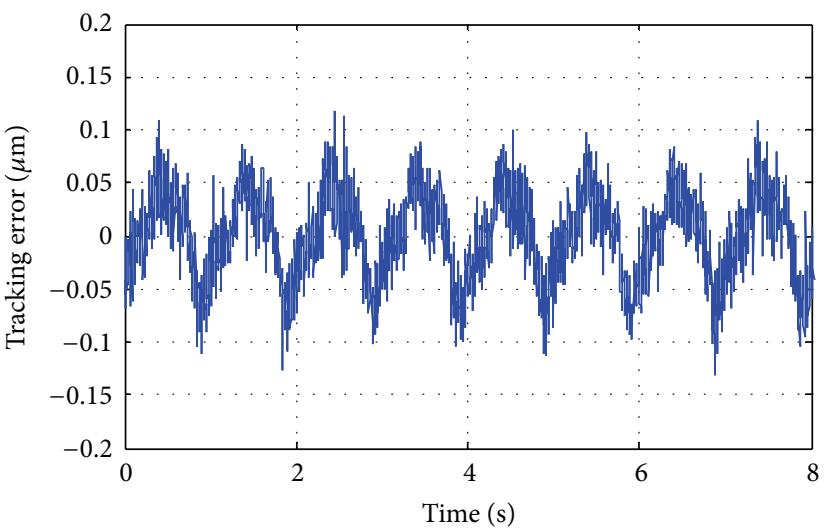

(c)

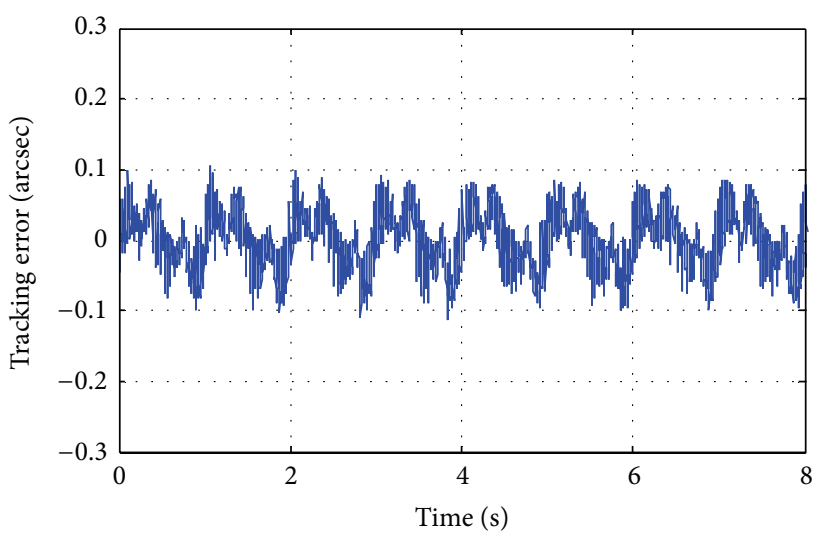

(e)

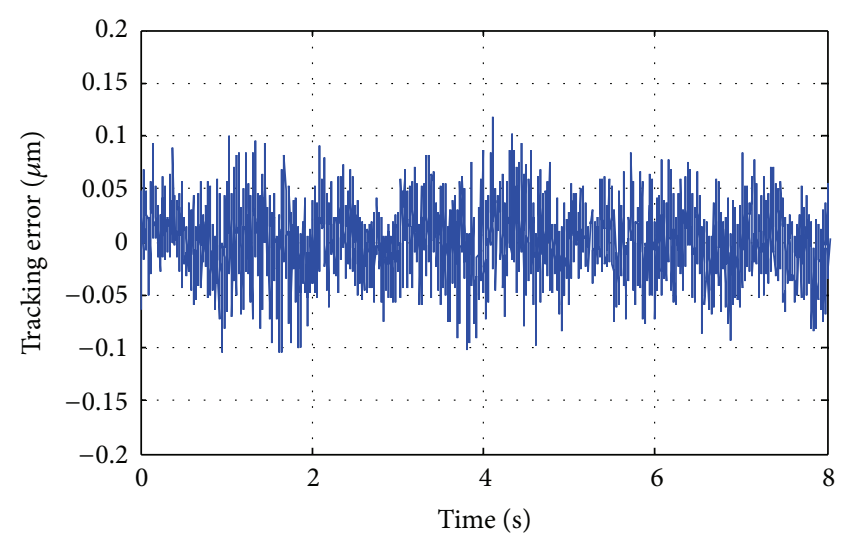

(b)

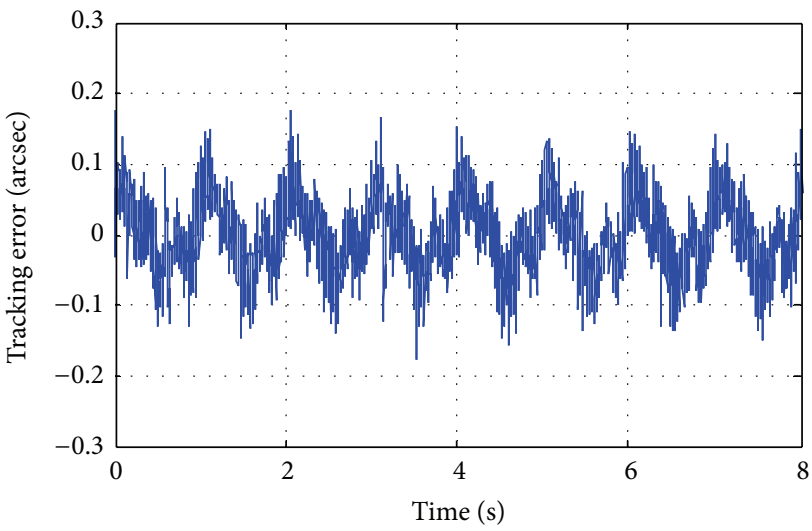

(d)

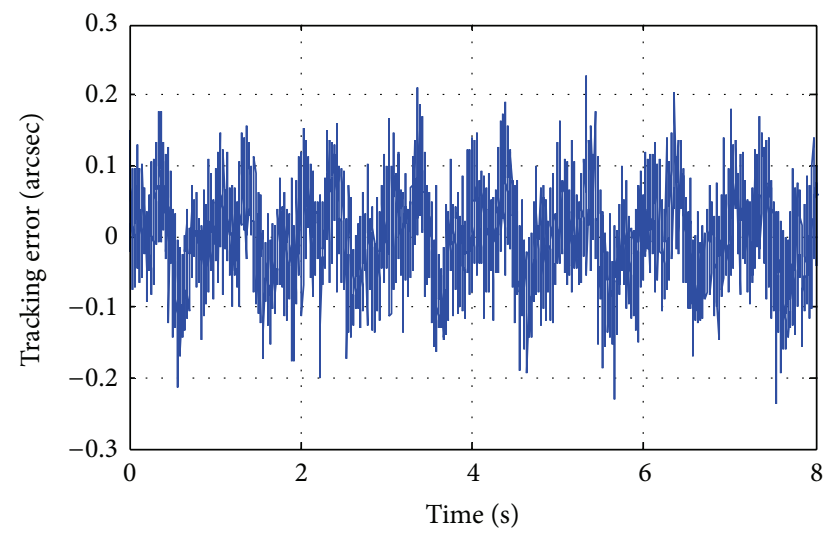

(f)

FIGURE $16: 1 \mathrm{~Hz}$ sine wave tracking result: (a) $x$-axis; (b) $y$-axis; (c) $z$-axis; (d) $\theta_{X}$; (e) $\theta_{Y}$; (f) $\theta_{Z}$.

This is almost equal to the residual error of the six-DOF measurement system.

4.3. Tracking Test. In this experiment, the stage was operated under closed loop control with feedforward compensation. Single axis tracking allowed the dynamic characteristic of the stage to be observed. Two input signals were tracked, $1 \mathrm{~Hz}$ and $5 \mathrm{~Hz}$ sine waves, both with amplitudes of $2.5 \mu \mathrm{m}$ and $5 \operatorname{arcsec}$ for the linear and angular axes, respectively. The results of this single axis tracking experiment are shown in Figures 16 and 17.

Because the orthogonality of a stacked stage is not very good it needs to be evaluated. In general this can be done by circular testing as described in ISO 230-4. The next test that had to be performed was that of dual-axis tracking. For this a circular test was run on three different planes, the $X Y, X Z$, and $Y Z$. The tracking signal used was a $1 \mathrm{~Hz}$ sine wave with amplitude of $2.5 \mu \mathrm{m}$. The results are shown in Figures 18(a) to $18(\mathrm{c})$, where it can be seen that (1) the larger roundness 


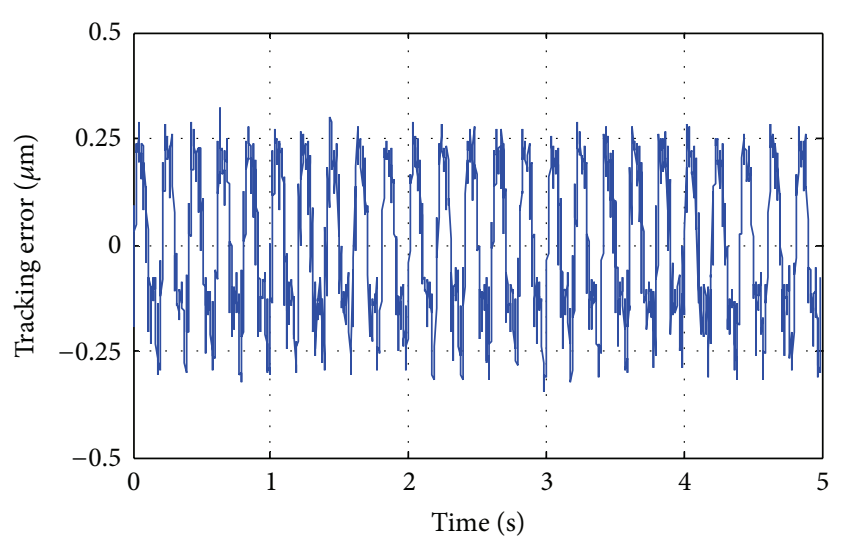

(a)

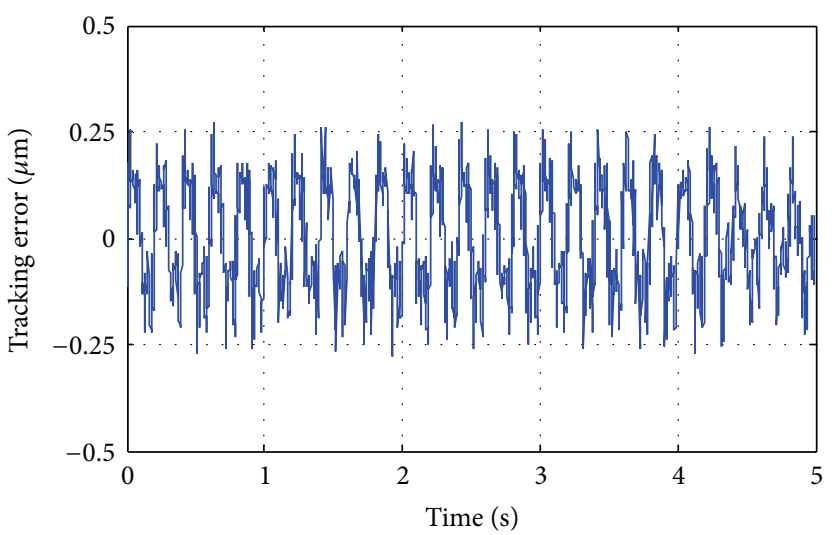

(c)

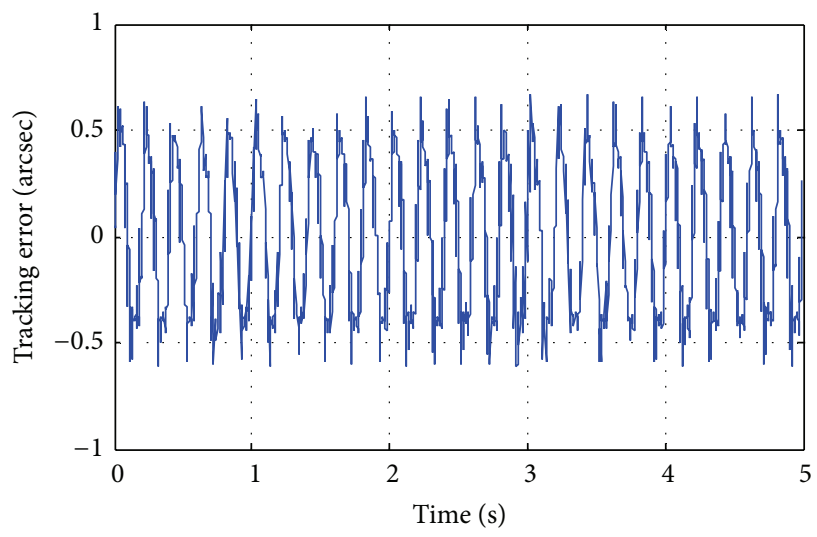

(e)

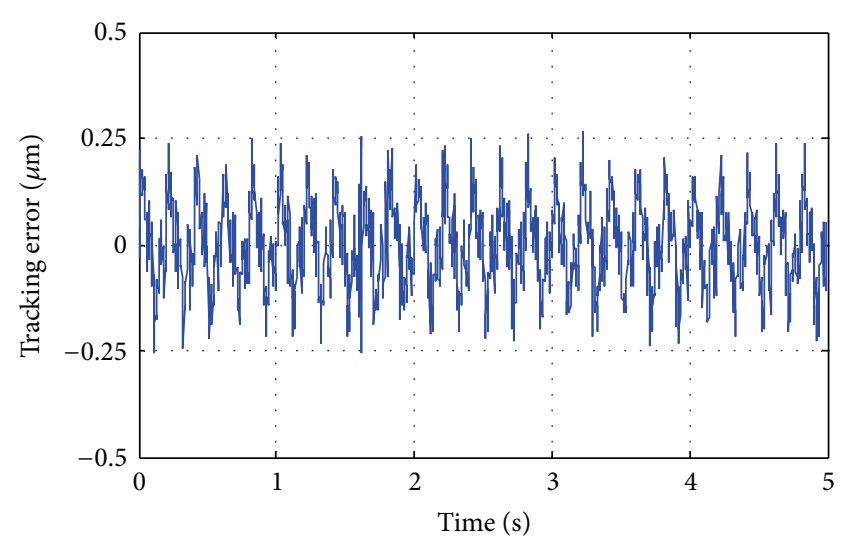

(b)

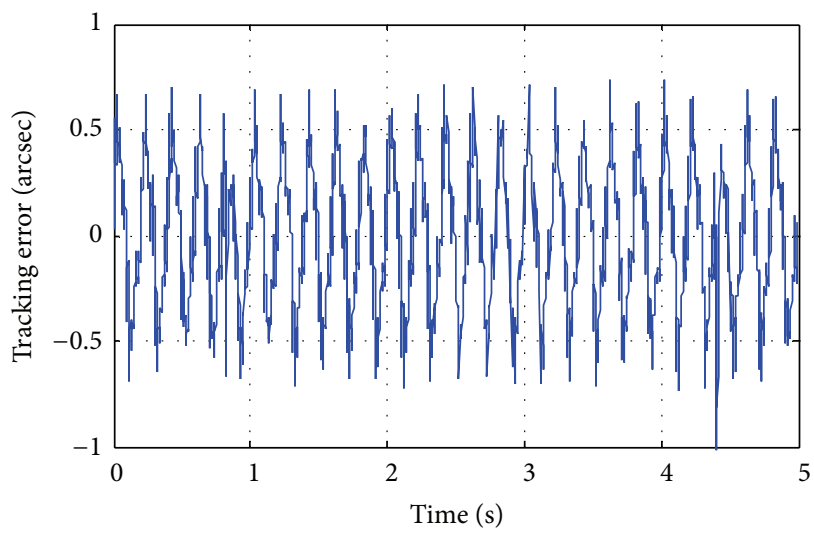

(d)

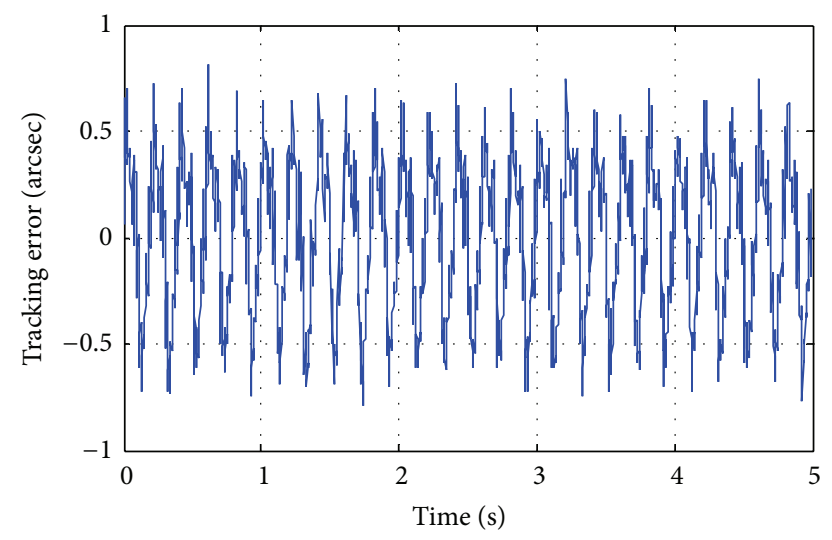

(f)

FIGURE $17: 5 \mathrm{~Hz}$ sine wave tracking result: (a) $x$-axis; (b) $y$-axis; (c) $z$-axis; (d) $\theta_{X}$; (e) $\theta_{Y}$; (f) $\theta_{Z}$.

error is inclined at -45 degrees in the $Y Z$ plane; (2) the larger roundness error is inclined at 45 degrees in the $X Z$ plane; (3) the larger round error is inclined at about zero degrees in the $X Y$ plane.

\section{Conclusions}

A flat six-DOF compensation stage controlled in closed loop has been proposed in this study. The feedback positional values are provided by a six-DOF optical measurement system comprised of three two-dimensional measurement modules. To reduce the effect of hysteresis, this study proposes a feedforward compensator based on a generic differential model in which hysteresis can be reduced by about $97 \%$. Although the $x$ - and $y$ - axes of the stage were linked as a four-bar mechanism, there was no displacement coupling problem. Positioning accuracy of the linear and angular movements is about $\pm 0.05 \mu \mathrm{m}$ and \pm 0.5 arcsec, respectively. From Figures 18(a) and 18(b), it can be seen that the $z$-axis is not exactly orthogonal with the $x$ - and $y$-axes, or movement 


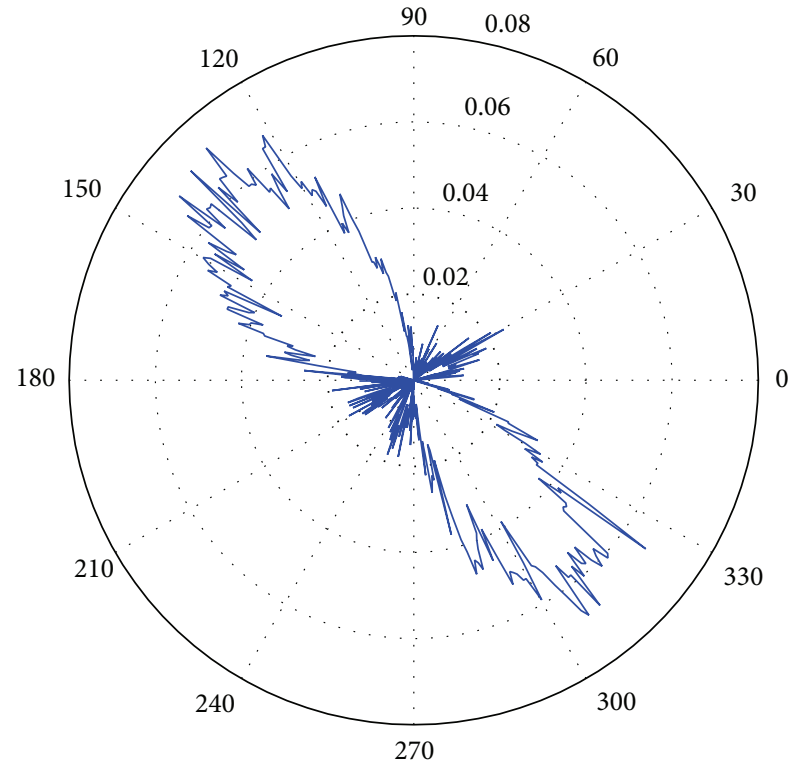

(a)

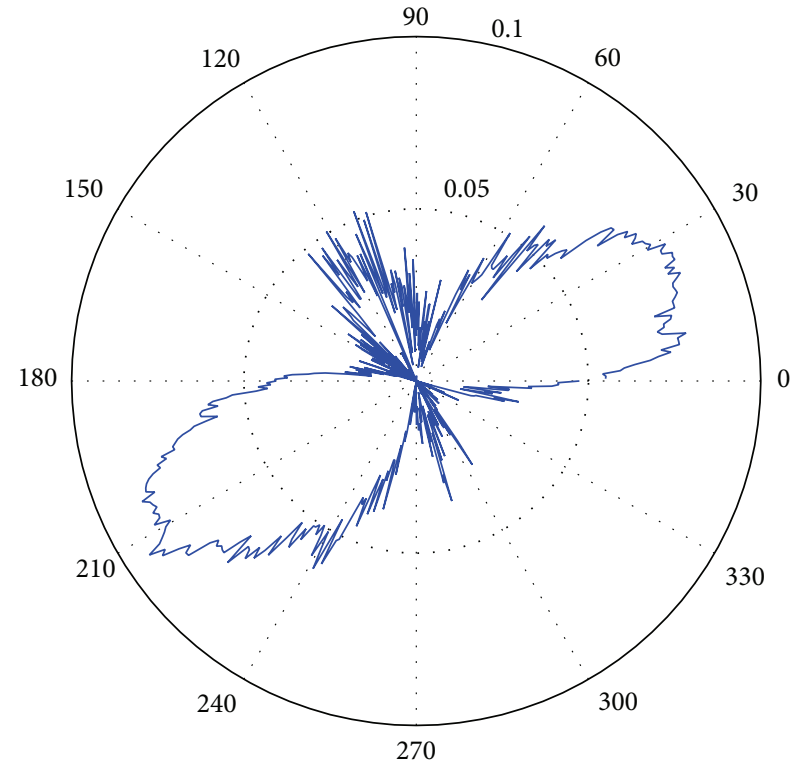

(b)

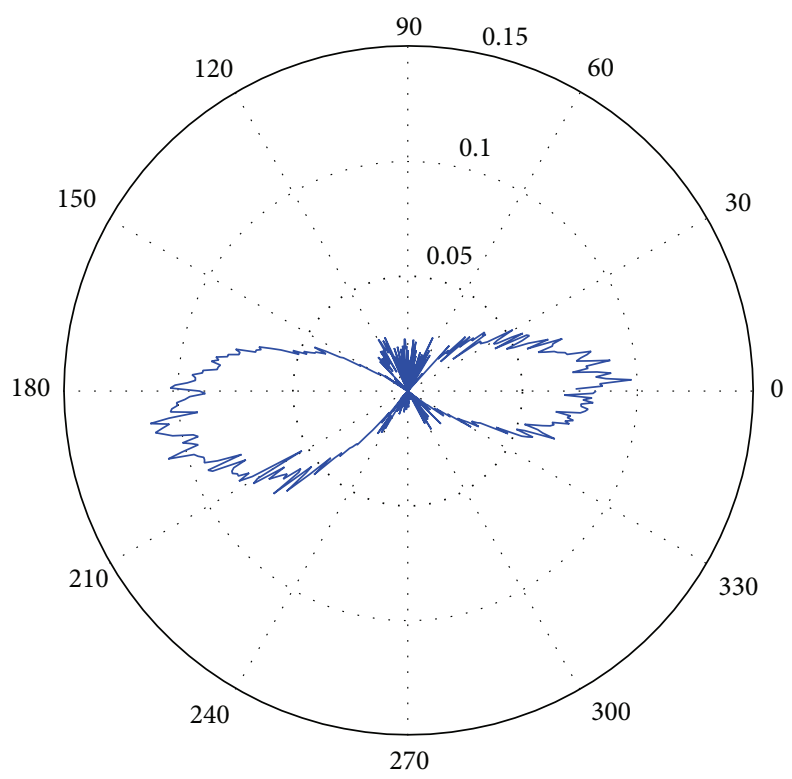

(c)

FIgURE 18: Circle test results for the 3-DOF compensation stage: (a) YZ plane; (b) XZ plane; (c) XY plane.

of $z$-axis is not synchronized with that of the $x$ - and $y$-axes. The displacement proportional difference between the $X$ and $Y$-axes is shown in Figure 18(c).

\section{Conflict of Interests}

The authors declare that there is no conflict of interests regarding the publication of this paper.

\section{Acknowledgment}

The work was supported by Ministry of Science and Technology, Taiwan (MOST 102-2218-E-005-014, MOST 102-2218-E005-012, and NSC.100-2221-E-005-091-MY3).

\section{References}

[1] C.-W. Lee and S.-W. Kim, "An ultraprecision stage for alignment of wafers in advanced microlithography," Precision Engineering, vol. 21, no. 2-3, pp. 113-122, 1997.

[2] W.-Y. Jywe, Y.-R. Jeng, C.-H. Liu et al., "A novel 5DOF thin coplanar nanometer-scale stage," Precision Engineering, vol. 32, no. 4, pp. 239-250, 2008.

[3] F.-J. Shiou, C.-J. Chen, C.-J. Chiang, K.-J. Liou, S.-C. Liao, and H.-C. Liou, "Development of a real-time closed-loop micro/nano-positioning system embedded with a capacitive sensor," Measurement Science and Technology, vol. 21, no. 5, Article ID 054007, 2010.

[4] J.-J. Kim, Y.-M. Choi, D. Ahn, B. Hwang, D.-G. Gweon, and J. Jeong, "A millimeter-range flexure-based nano-positioning 
stage using a self-guided displacement amplification mechanism," Mechanism and Machine Theory, vol. 50, pp. 109-120, 2012.

[5] J. Guo, S. K. Chee, T. Yano, and T. Higuchi, "Micro-vibration stage using piezo actuators," Sensors and Actuators A: Physical, vol. 194, pp. 119-127, 2013.

[6] A. J. Fleming, "A review of nanometer resolution position sensors: operation and performance," Sensors and Actuators A: Physical, vol. 190, pp. 106-126, 2013.

[7] S. Polit and J. Dong, "Development of a high-bandwidth XY nanopositioning stage for high-rate micro-/nanomanufacturing," IEEE/ASME Transactions on Mechatronics, vol. 16, no. 4, pp. 724-733, 2011.

[8] Y. Shimizu, Y. Peng, J. Kaneko et al., "Design and construction of the motion mechanism of an XY micro-stage for precision positioning," Sensors and Actuators A: Physical, vol. 201, pp. 395-406, 2013.

[9] H. Kim and D.-G. Gweon, "Development of a compact and long range $\mathrm{XY} \theta \mathrm{z}$ nano-positioning stage," Review of Scientific Instruments, vol. 83, Article ID 085102, 2012.

[10] R. Fesperman, O. Ozturk, R. Hocken et al., "Multi-scale alignment and positioning system-MAPS," Precision Engineering, vol. 36, no. 4, pp. 517-537, 2012.

[11] D. M. Brouwer, B. R. de Jong, and H. M. J. R. Soemers, "Design and modeling of a six DOFs MEMS-based precision manipulator," Precision Engineering, vol. 34, no. 2, pp. 307-319, 2010.

[12] C.-H. Liu, C.-L. Chen, H.-W. Lee, and W.-Y. Jywe, "Improvement of the nonlinear dynamic response of a Z-tilts lead zirconate titanate-based compensation stage using the capacitor insertion method," Review of Scientific Instruments, vol. 80, no. 11, Article ID 115112, 2009.

[13] H. J. Lee, H. C. Kim, H. Y. Kim, and D. G. Gweon, "Optimal design and experiment of a three-axis out-of-plane nano positioning stage using a new compact bridge-type displacement amplifier," Review of Scientific Instruments, vol. 84, no. 11, Article ID 115103, 2013.

[14] I. D. Mayergoyz, "Mathematical models of hysteresis," IEEE Transactions on Magnetics, vol. 22, no. 5, pp. 603-608, 1986.

[15] K. K. Leang and S. Devasia, "Design of hysteresis-compensating iterative learning control for piezo-positioners: application to atomic force microscopes," Mechatronics, vol. 16, no. 3-4, pp. 141-158, 2006.

[16] C. Xinkai, "Advanced control for magnetostrictive actuated nano-stage," in Proceedings of the IEEE International Conference on Mechatronics and Automation (ICMA '13), pp. 749-754, Takamatsu, Japan, 2013.

[17] C.-Y. Lin and P.-Y. Chen, "Precision tracking control of a biaxial piezo stage using repetitive control and double-feedforward compensation," Mechatronics, vol. 21, no. 1, pp. 239-249, 2011.

[18] G.-Y. Gu and L.-M. Zhu, "Motion control of piezoceramic actuators with creep, hysteresis and vibration compensation," Sensors and Actuators A: Physical, vol. 197, pp. 76-87, 2013.

[19] C. Ru and L. Sun, "Improving positioning accuracy of piezoelectric actuators by feedforward hysteresis compensation based on a new mathematical model," Review of Scientific Instruments, vol. 76, no. 9, Article ID 095111, 2005.

[20] R. Changhai and S. Lining, "Hysteresis and creep compensation for piezoelectric actuator in open-loop operation," Sensors and Actuators A: Physical, vol. 122, no. 1, pp. 124-130, 2005.
[21] H. Hu, H. M. S. Georgiou, and R. Ben-Mrad, "Enhancement of tracking ability in piezoceramic actuators subject to dynamic excitation conditions," IEEE/ASME Transactions on Mechatronics, vol. 10, no. 2, pp. 230-239, 2005.

[22] D. Croft, G. Shedd, and S. Devasia, "Creep, hysteresis, and vibration compensation for piezoactuators: atomic force microscopy application," in Proceedings of the American Control Conference, pp. 2123-2128, Chicago, Ill, USA, June 2000.

[23] D. Croft and S. Devasia, "Hysteresis and vibration compensation for piezoactuators," Journal of Guidance, Control, and Dynamics, vol. 21, no. 5, pp. 710-717, 1998.

[24] T. S. Low and W. Guo, "Modeling of a three-layer piezoelectric bimorph beam with hysteresis," Journal of Microelectromechanical Systems, vol. 4, no. 4, pp. 230-237, 1995.

[25] H. J. M. T. A. Adriaens, W. L. de Koning, and R. Banning, "Modeling piezoelectric actuators," IEEE/ASME Transactions on Mechatronics, vol. 5, no. 4, pp. 331-341, 2000.

[26] R. Banning, W. L. de Koning, H. J. Adriaens, and R. K. Koops, "State-space analysis and identification for a class of hysteretic systems," Automatica, vol. 37, no. 12, pp. 1883-1892, 2001.

[27] J.-D. Kim and S.-R. Nam, "A piezoelectrically driven micropositioning system for the ductile-mode grinding of brittle materials," Journal of Materials Processing Technology, vol. 61, no. 3, pp. 309-319, 1996.

[28] M. Goldfarb and N. Celanovic, "Modeling piezoelectric stack actuators for control of micromanipulation," IEEE Control Systems Magazine, vol. 17, no. 3, pp. 69-79, 1997.

[29] C.-J. Lin and S.-R. Yang, "Precise positioning of piezo-actuated stages using hysteresis-observer based control," Mechatronics, vol. 16, no. 7, pp. 417-426, 2006.

[30] H. G. Kim, "Nano positioning control for dual stage using minimum order observer," Journal of Mechanical Science and Technology, vol. 26, no. 3, pp. 941-947, 2012.

[31] C. Canudas de Wit, H. Olsson, K. J. Astrom, and P. Lischinsky, "A new model for control of systems with friction," IEEE Transactions on Automatic Control, vol. 40, no. 3, pp. 419-425, 1995.

[32] T.-Y. Lin, Y.-C. Pan, and C. Hsieh, "Precision-limit positioning of direct drive systems with the existence of friction," Control Engineering Practice, vol. 11, no. 3, pp. 233-244, 2003.

[33] C.-K. Chen, C.-H. Liu, and C.-H. Cheng, "Multi-DOF incremental optical encoder with laser wavelength compensation," Smart Science, vol. 1, pp. 1-12, 2013.

[34] C.-H. Liu, H.-L. Huang, and H.-W. Lee, "Five-degrees-offreedom diffractive laser encoder," Applied Optics, vol. 48, no. 14, pp. 2767-2777, 2009.

[35] W.-Y. Jywe, Y.-R. Jeng, Y.-F. Teng, C.-H. Liu, Y.-T. Jian, and H.S. Wang, "Development of a novel multi-axis nano-positioning and the spiral tracking control," Journal of the Chinese Society of Mechanical Engineers, vol. 30, no. 4, pp. 343-350, 2010.

[36] C.-H. Liu, W.-Y. Jywe, Y.-R. Jeng, T.-H. Hsu, and Y.-T. Li, "Design and control of a long-traveling nano-positioning stage," Precision Engineering, vol. 34, no. 3, pp. 497-506, 2010. 


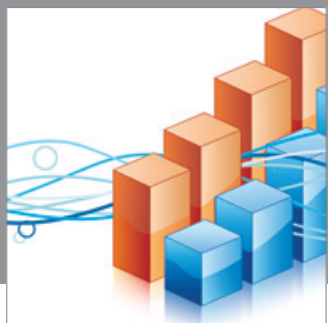

Advances in

Operations Research

mansans

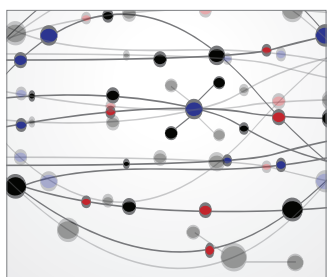

The Scientific World Journal
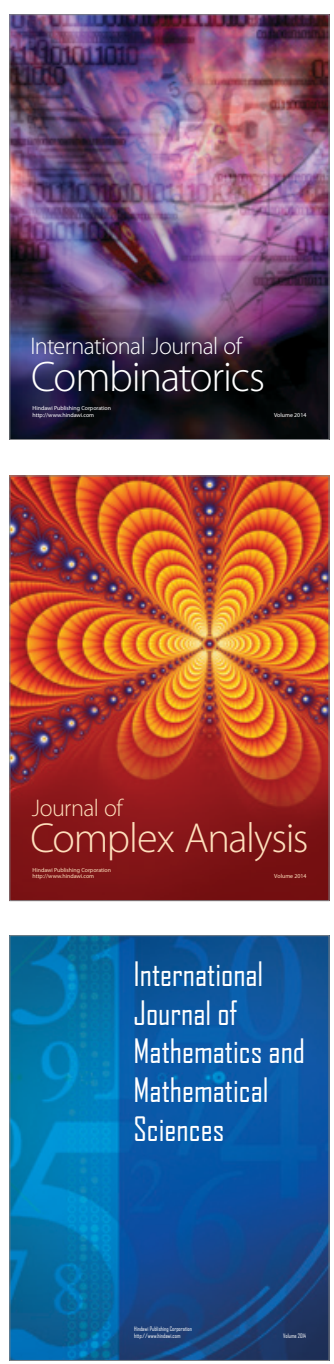
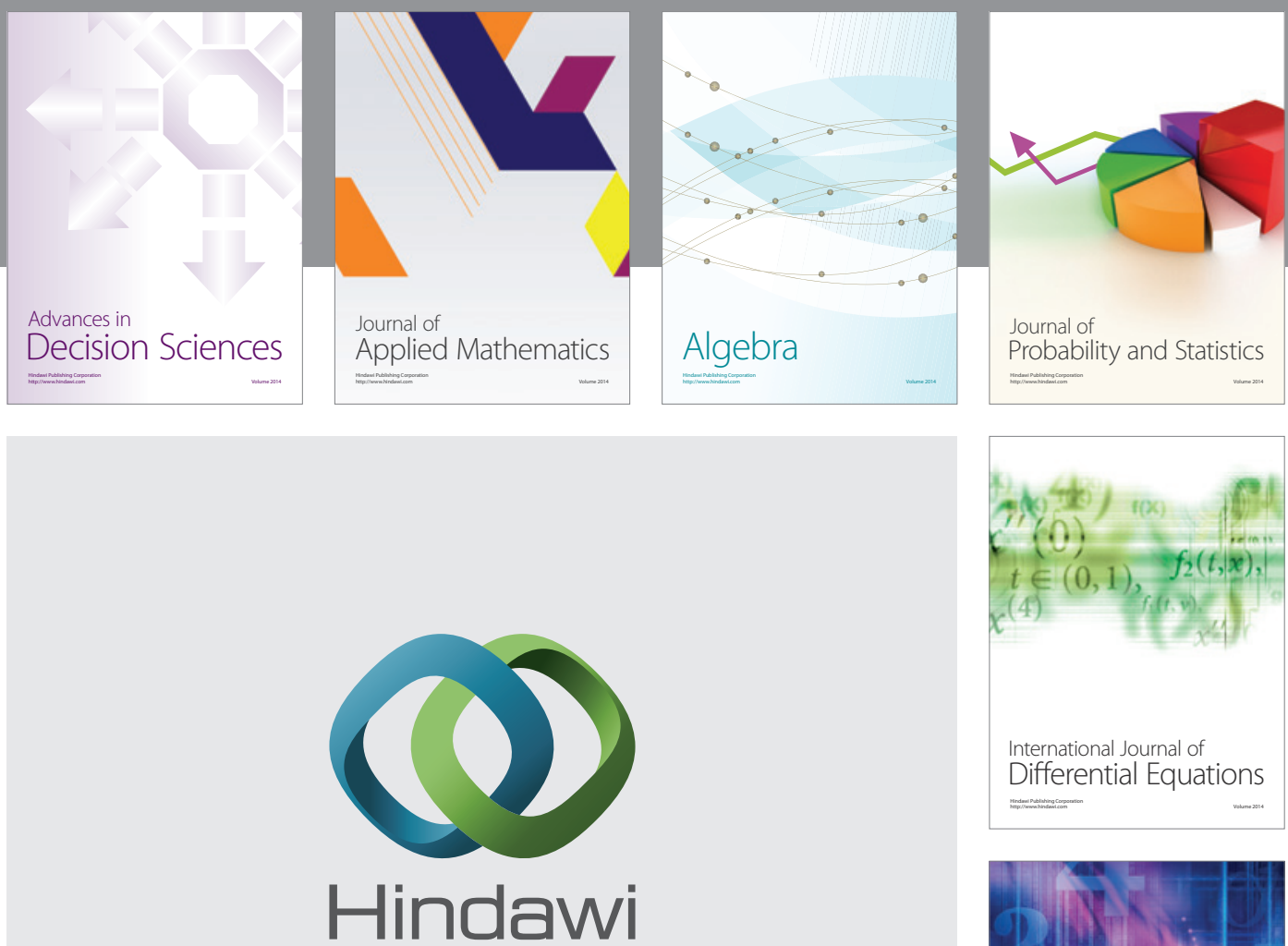

Submit your manuscripts at http://www.hindawi.com
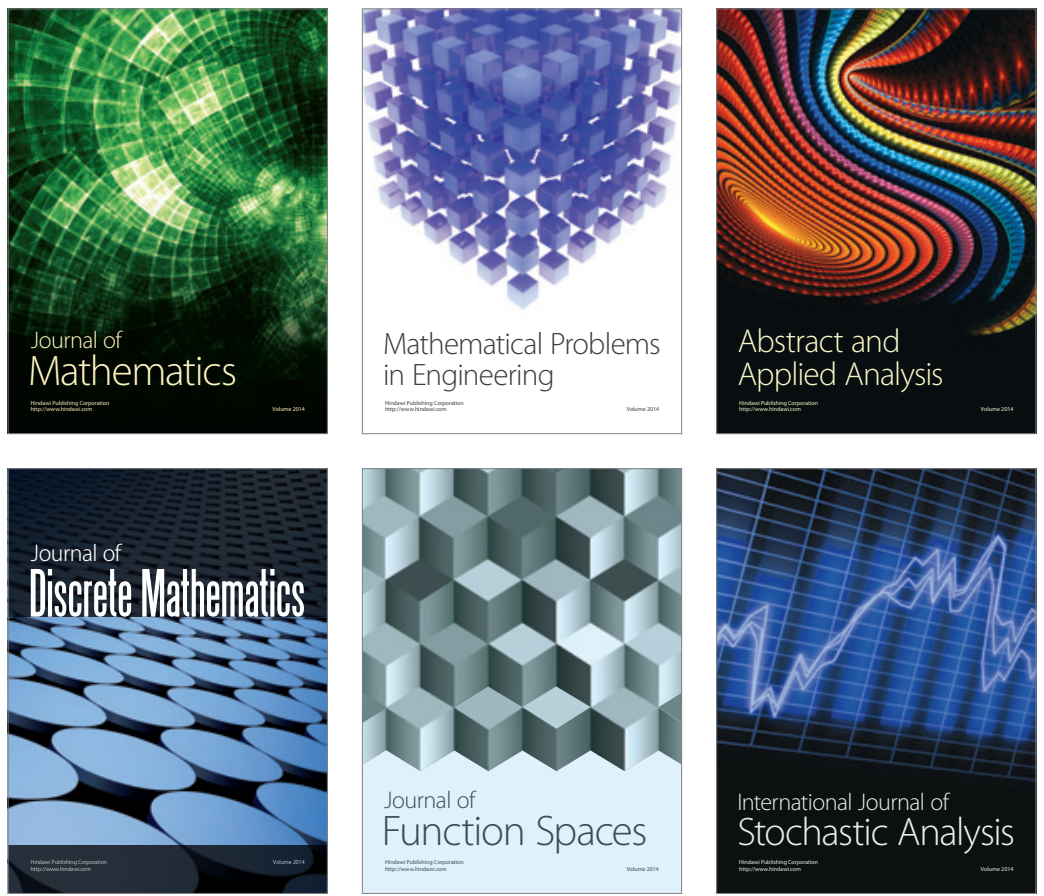

Journal of

Function Spaces

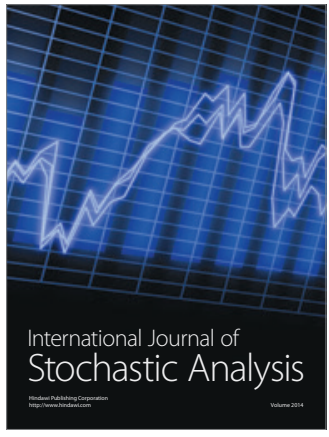

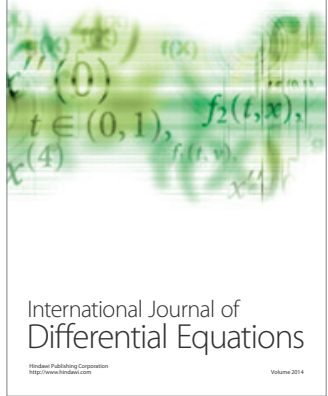
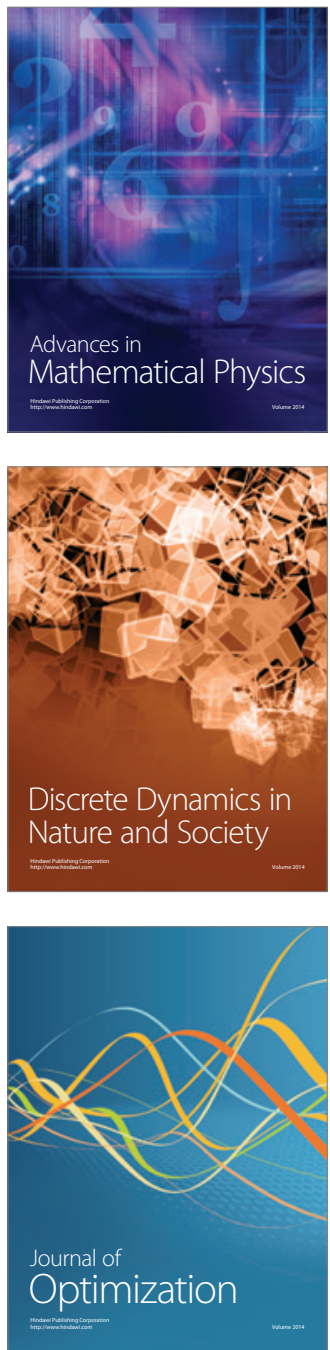